\title{
Mapeamento dos padrões de atuação dos países nas Cadeias Globais de Valor e os ganhos em termos de mudança estrutural
}

\author{
AUTORES: \\ Marta dos Reis Castilho - Universidade Federal do Rio de Janeiro \\ Ludmila Macedo Corrêa - Universidade Federal Rural do Rio de Janeiro \\ Eduardo Costa Pinto - Universidade Federal do Rio de Janeiro
}

\begin{abstract}
Resumo
Este artigo tem como objetivo mapear padrões de atuação dos países nas Cadeias Globais de Valor (CGV) e os respectivos ganhos, identificando-se sob quais circunstâncias a atuação nessas cadeias foi acompanhada de mudança estrutural. Os padrões de atuação referem-se à inserção dos países nas CGV e possíveis evoluções através de diferentes tipos de upgrading. O mapeamento foi feito com uma amostra de 40 países entre 1995 e 2008, utilizando-se 12 indicadores que captaram características inerentes a participação neste processo. Em função da quantidade de informação, foi utilizada a técnica de clusters, que associado a outros critérios analíticos, permitiu identificar seis padrões de inserção e upgrading dos países nas cadeias globais associados ao potencial de mudança estrutural. Verificou-se que a intensidade da mudança estrutural associa-se a padrões específicos de atuação nas cadeias referentes ao upgrading funcional e de cadeia, sendo que este último, ocorrendo em países situados em estágios produtivos iniciais.
\end{abstract}

\section{Palavras chave:}

Cadeias Globais de Valor, upgrading, estágio produtivo, mudança estrutural, técnica de cluster.

\begin{abstract}
This article aims to map the acting patterns of the countries in the Global Value Chains (GVC) and their gains, in order to identify under what circumstances, the acting in these chains were accompanied by structural change. The acting patterns refer themselves to insertion of countries in GVC and possible evolutions through different types of upgrading. The mapping was done with a sample of 40 countries between 1995 and 2008, using 12 indicators that captured characteristics of the participation in this process. Due to the amount of information, we used the cluster technique, which combined with other analytical criteria, identified six patterns of insertion and upgrading of countries in global chains associated to structural change potential. It was found that the intensity of structural change is associated with specific acting patterns in the chains related to the functional and chain upgrading, and this latter, occurring in countries located at the initial productive stage.
\end{abstract}

Key words: Global Value Chain, upgrading, productive stage, structural change, cluster technique.

Área 2: Comércio internacional, cadeias de valor e internacionalização

Jel: F1, F14, 01 


\section{Mapeamento dos padrões de atuação dos países nas Cadeias Globais de Valor e os ganhos em termos de mudança estrutural}

\section{INTRODUÇÃO}

O processo de fragmentação da produção internacional e a formação das Cadeias Globais de Valor (CGV) possibilitaram a inserção de diversos países em desenvolvimento neste paradigma de produção com diferentes implicações sobre os mesmos. Para alguns, a participação contribuiu para o crescimento do produto e exportações (denominados ganhos de curto prazo), enquanto para outros, estes se estenderam ao longo do tempo, representando mudanças na composição das estruturas produtivas dos países em direção a estágios produtivos mais elevados, representando uma mudança estrutural (denominados ganhos de longo prazo).

Diante dos diferentes tipos de ganhos obtidos pelos países nessas cadeias de valor, o presente trabalho tem como objetivo fazer um mapeamento dos padrões de atuação dos países nas cadeias (inserção e upgrading) e os ganhos decorrentes desse processo, buscando identificar sob quais circunstâncias a atuação nas cadeias de valor foi acompanhada de mudança estrutural.

Como a evolução dos países - ou o processo de upgrading - é multidimensional, optou-se por realizar a análise com múltiplos indicadores combinados (12 no total), de forma a captar o máximo de características inerentes ao processo de upgrading dos países nas CGV - amostra de 40 países ${ }^{1}$ para o período entre 1995 e 2008. Em função da quantidade de informação, foi utilizada a técnica de clusters, que associado a outros critérios analíticos, permitiu identificar padrões de atuação dos países nas cadeias globais associados ao potencial de mudança estrutural.

A adoção da análise conjunta de indicadores para examinar o upgrading dos países na cadeia, representa um ganho analítico em relação à boa parte dos trabalhos que lidam com o tema, por estes se basearem frequentemente em estudos de caso, com baixa capacidade de generalização e comparabilidade.

\section{CADEIAS GLOBAIS DE VALOR, PADRÕES DE ATUAÇÃO (INSERÇÃO E UPGRADING) DOS PAÍSES EM DESENVOLVIMENTO E MUDANÇA ESTRUTURAL}

$\mathrm{O}$ processo de fragmentação internacional da produção e formação das CGV se expandiu significantemente nas últimas duas décadas como estratégia de internacionalização das grandes corporações que estavam em busca de maior eficiência dado o aumento da concorrência e das novas circunstâncias internacionais referente à liberalização e desregulamentação dos mercados. $\mathrm{O}$ fatiamento e a distribuição da cadeia produtiva de processos produtivos descontínuos em diferentes regiões foram facilitados pela redução dos custos de transporte e de transação decorrentes dos avanços tecnológicos e da redução das barreiras protecionistas. Esse novo paradigma imprimiu novas características à divisão internacional do trabalho, conduzindo a uma reorganização da produção e do comércio em torno de redes globais e regionais e reposicionando os países em desenvolvimento no cenário internacional.

Neste contexto, a produção dos bens está fragmentada nas diferentes regiões, em que a localização das etapas está condicionada às vantagens comparativas "caleidoscópicas" encontradas nos diversos países. Este termo foi desenvolvido em Bhagwati e Deheja apud Memedovic e Iapadre (2009) para referir-se às vantagens em cada etapa do processo produtivo, em oposição às vantagens comparativas em termos de bens finais da teoria tradicional. Esta mudança é decorrente do fato de que as diferentes etapas do processo produtivo geram diferentes níveis de agregação de valor, e que a possibilidade de separá-las, permite que os países se concentrem em capturar valor adicionado (VA) em etapas específicas. Segundo Baldwin (2012), as etapas que geram maior VA são os estágios pré e pós-fabricação, formados basicamente por serviços - concepção, design, P\&D, vendas, marketing e serviços pós-venda - cujos potenciais de criação de VA das atividades são relacionados na "smile curve".

\footnotetext{
${ }^{1}$ Da América: Estados Unidos, Canadá, México, Chile, Brasil, Argentina. Da Europa: Alemanha, Reino Unido, Irlanda, França, Áustria, Bélgica, Holanda, Itália, Espanha, Portugal, Hungria, República Eslováquia, República Checa, Polônia, Bulgária e Romênia. Da Ásia: Japão, Coreia, Hong Kong, Cingapura, Taiwan, Malásia, Filipinas, Tailândia, Indonésia, China, Índia, Vietnã, Camboja, Turquia, Israel e Rússia. Da Oceania e da África: Austrália e África do Sul.
} 
Dado os diferenciais de captura de valor adicionado, observam-se os países em desenvolvimento atuando cada vez mais na produção de produtos manufaturados - em atividades de processamento e montagem de produto final, enquanto os desenvolvidos têm aumentado sua participação em atividades de maior VA como produção de peças e componentes ou restringindo-se a segmentos de serviços como atividades de criação do produto - design e P\&D (MEMEDOVIC \& IAPADRE, 2009).

Sob uma perspectiva de firmas líderes, sediadas geralmente nos países desenvolvidos, Sarti e Hiratuka (2010) ressaltam que diante dessa assimetria de captura de VA, a descentralização da cadeia de produção ocorre de forma hierárquica, com a maior parcela do valor adicionado permanecendo em geral na matriz destas corporações. E como são essas que controlam o restante das firmas envolvidas (firmas fornecedoras/contratadas sediadas em geral nos países em desenvolvimento) no que diz respeito à natureza dos contratos e transferência de tecnologia, a descentralização da produção ocorre simultaneamente a maior concentração do poder de comando sobre a criação de VA nas cadeias. Milberg e Winkler (2013) acrescentam ainda que a manutenção da captura assimétrica de VA entre as partes envolvidas é endógena as estratégias das corporações, evidenciando a resistência ou impedimento a qualquer alteração de posição dos países em desenvolvimento na atuação nessas cadeias de valor.

Numa perspectiva contrária, de empresas contratadas nos países em desenvolvimento, observa-se que a atração de etapas do processo produtivo intensivos em mão-de-obra (com potencial reduzido de criação de VA) dos países centrais, embora venha sendo moldada pelos interesses das empresas líderes, ainda garante para os países em desenvolvimento, possibilidades de obtenção de ganhos. A inserção desses países neste paradigma produtivo, além de contribuir para a geração de emprego e renda local e aumento das exportações, implicou também em muitos casos, na alteração da composição dessas exportações. Anteriormente esses países caracterizavam-se por serem grandes exportadores de produtos primários, mas com o processo de fragmentação internacional da produção, suas pautas de exportação passaram a apresentar um peso significativo das manufaturas, inclusive, as intensivas em tecnologia.

Neste sentido, vê-se a participação nessas redes internacionais de produção representando para muitos, um avanço em termos industrialização, que reflete no curto prazo em um aumento das exportações, do emprego e da renda (UNCTAD, 2013; MEMEDOVIC e IAPADRE, 2009). Dentre esses países, observa-se ainda que para alguns, os ganhos se estenderam para o longo prazo, com a maior atuação em segmentos industriais gerando efeitos de transbordamento para outros setores, alavancando o desenvolvimento de segmentos mais sofisticados, e com isso, o aumento da produtividade do país.

Para aqueles cujos ganhos restringiram ao curto prazo, a alteração do padrão de especialização da economia decorrente da inserção nas cadeias pode limitar-se ao setor exportador, com poucos efeitos de encadeamento sobre a economia e a variação da produtividade. Neste caso, a sofisticação da pauta de exportação não reflete na melhora da estrutura produtiva do país, podendo caracterizar um aprisionamento do país em atividades de baixo VA. A pouca endogenização tecnológica dessa atividade e o limitado dinamismo econômico decorrente, refletirá no lock-in do país em sua estrutura de produção ${ }^{2}$.

Diante disso, constata-se que os ganhos obtidos com as CGV têm relação direta com a etapa de atuação dentro da cadeia produtiva e o efeito de transbordamento desta atividade sobre o restante da economia (tanto via encadeamento quanto potencial de learning da atividade). Assim, a existência de efeitos de transbordamentos (e os ganhos potenciais decorrentes) pode servir de incentivo a uma atuação dos países nas cadeias em atividades intensivas em conhecimento e/ou em cadeias de valor mais sofisticadas tecnologicamente, com efeitos positivos sobre a composição de sua estrutura produtiva e do nível de produtividade, representando um ganho de longo prazo.

Paralelamente aos distintos resultados obtidos, observa-se que a participação dos países nessas cadeias também vem ocorrendo sob diferentes padrões de atuação. Esses padrões referem-se à localização nas cadeias em termos de atividade desenvolvida e possíveis evoluções ocorridas na mesma sob a forma de diferentes tipos de upgrading. Esse termo upgrading é referido por Milberg e Winkler (2013) como

\footnotetext{
${ }^{2}$ Um exemplo clássico de aprisionamento dos países em desenvolvimento refere-se à armadilha da renda média, em que os países ao atingir um nível médio de renda, não conseguem avançar para estágios de desenvolvimento superior. Isso ocorre quando o país deixa de competir via preço com as economias de baixa renda, em virtude da elevação dos seus níveis salariais, sem ter criado condições para competir com economias mais avançadas, cujas estruturas produtivas baseiam-se em produtos intensivos em conhecimento (EICHENGREEN, 2011).
} 
um mecanismo de superação do padrão de especialização dos países ditado pelas vantagens comparativas, através de movimentos ao longo da cadeia de valor em busca de maior captura de valor adicionado.

Assim, em alguns países, a atuação restringe-se a atividade desempenhada durante a inserção, enquanto em outros, observa-se uma atuação mais abrangente, com avanço destes em termos de maior eficiência de seus processos produtivos (upgrading de processo) ou de melhores produtos produzidos (upgrading de produto), ou ainda um avanço para cadeias de valor mais sofisticadas (upgrading de cadeia) e/ou no tipo de atividade desempenhada em termos de intensidade de conhecimento (upgrading funcional $)^{3}$. Os diferentes padrões de atuação nas cadeias implicam também em diferentes resultados.

Com o upgrading de produto e/ou processo, pode haver um fortalecimento da posição do país nas cadeias, em que com o apoio da firma líder (decorrente do maior retorno proporcionado para elas), consegue ter ganhos de curto prazo referente à exportação, produto e emprego, sem no entanto, ser suficiente para alteração de sua estrutura produtiva. Já o upgrading de cadeia e/ou funcional, em função do efeito de transbordamento de cadeias ou atividades mais sofisticadas, potencializa os ganhos da atuação, podendo refletir sobre a composição de suas estruturas de produção. Embora essa evolução em temos padrão de atuação seja positiva para os países, ela é desestimulada pelas empresas líderes por temer perder espaço na captura de VA nestas cadeias.

Sobre os efeitos do upgrading de cadeia e principalmente o funcional, destaca-se ainda o seu potencial na sustentação dos ganhos da participação nas cadeias ao longo do tempo. Neste tipo de evolução, os países empregam mais mão-de-obra qualificada fazendo com que suas posições nas cadeias não fiquem vulneráveis à inserção de economias mais atrasadas, atuantes em atividades intensivas em trabalho não-qualificado e com baixos salários.

Ainda a respeito dos padrões de atuação, ressalta-se que estes podem ser analisados em termos de criação de VA doméstico. Baseado nisso, UNCTAD (2013) associou as diferentes formas de atuação a um processo evolutivo dos países nas cadeias, cuja dinâmica consiste na integração as CGV, podendo prosseguir para o upgrading de produto e processo, e por último, o upgrading de cadeia e funcional. A inserção dos países em desenvolvimento ocorre em etapas de baixo VA (geralmente atividades de montagem e processamento e com elevada importação de insumos), cuja fase inicial caracteriza-se pelo aumento da participação nas CGV associado à baixa (ou redução) criação VA doméstico. Posteriormente ou mesmo em paralelo, estes podem desenvolver melhorias nos processos produtivos através do upgrading de processo e de produto, implicando no aumento da produtividade do segmento e no VA criado domesticamente. Neste momento, têm-se crescimento da participação nas cadeias e maior captura de valor adicionado local. E, por fim, como uma diversificação da produção, pode ocorrer um movimento para atividades de maior VA nas cadeias (tarefas intensivas em conhecimento) ou para cadeias de maior sofisticação tecnológica - upgrading funcional ou de cadeia. Inicialmente esse movimento pode até provocar redução da participação do VA doméstico nas exportações, dada à necessidade de maior importação de insumos, mas que refletirá no aumento do valor bruto da produção. Vê-se com isso, a possibilidade de ocorrência de upgrading simultaneamente a redução do VA doméstico.

Além da possibilidade da participação dos países nas cadeias ocorrer sob diferentes padrões de atuação, estes países podem estar situados também em diferentes estágios produtivos. Os estágios são definidos, aqui, a partir da predominância de determinados setores nestas economias que irão refletir em sua perfomance econômica, em termos de emprego, produto, exportação e crescimento econômico.

Economias em estágios produtivos iniciais têm suas estruturas produtivas compostas basicamente por manufaturas de baixa intensidade tecnológica e intensivas em mão-de-obra e/ou recursos naturais (indústria alimentícia, têxtil, vestuário). Esses setores têm grande potencial de criação de emprego nestas economias, embora de baixa qualificação. Uma estrutura de produção com predomínio desses setores caracteriza países decolando seu processo de industrialização, com esse padrão de especialização contribuindo para aumentar a produtividade e o crescimento do produto (lei Kaldor-Verdoon), entretanto, ainda limitado quanto à acumulação de capital devido à baixa intensidade tecnológica dos segmentos.

$\mathrm{O}$ avanço no estágio produtivo refere-se à maior participação de manufaturas de média e alta intensidade tecnológica, mas ainda com relevância as de intensidade tecnológica em níveis mais baixos.

\footnotetext{
${ }^{3}$ Para o aprofundamento dos diferentes upgrading, consultar Pietrobelli \& Rabellotti (2006) e Humphrey \& Schimtz (2002).
} 
O êxito do processo de industrialização induz os países à diversificação para segmentos mais sofisticados e de maior rentabilidade como, por exemplo, metais básicos e produtos fabricados de metais, e posteriormente, num aprofundamento deste processo, para indústrias de equipamentos de transporte e eletrônicos. Embora as indústrias intensivas em tecnologia empreguem menos que as de baixa tecnologia, geram empregos mais qualificados. Com isso, além da maior produtividade do segmento, a articulação significativa existente entre as atividades industriais com os outros setores (via demanda por insumos e serviços) implicará em efeitos de transbordamento sobre a economia, contribuindo mais intensamente para o aumento da produtividade.

E por fim, em estágios mais avançados, têm-se países com estruturas produtivas com predomínio de setores intensivos em conhecimento, característico nas manufaturas de alta intensidade tecnológica máquinas, equipamento eletrônicos e de transporte - e também de serviços associados a essas atividades serviços financeiros, de transporte, TI. Deve-se ressaltar, no entanto, que com o processo de fragmentação internacional da produção, o padrão de especialização ocorre mais em atividades do que em setores. Assim, os países neste estágio produtivo, restringem-se as atividades intensivas em conhecimento destes setores e de outros (desenvolvimento de produto e serviços pós-manufatura) que são pouco geradoras de emprego, mas no geral, mão-de-obra qualificada. Neste estágio, a competitividade baseia-se na busca constante pela maior diferenciação e inovação, cujos aspectos são responsáveis pela fronteira tecnológica existente. A elevada produtividade destes setores, com grande encadeamento para o restante da economia, contribui para a alta taxa de acumulação de capital destes países.

Assim, o padrão de atuação dos países nas CGV influencia seu atual estágio produtivo, podendo impulsionar a economia em direção a estágios mais avançados, representando uma mudança estrutural. Este termo refere-se à alteração da composição da estrutura produtiva decorrente de diferentes distribuições dos fatores de produção entre os setores, rumo a setores mais produtivos (MEMEDOVIC e IAPADRE, 2009; UNIDO, 2013). Com isso, têm-se um processo de acumulação de capital e incorporação do progresso técnico (endogenização tecnológica) com crescente participação de setores intensivos em tecnologia e conhecimento implicando no aumento da produtividade de toda a economia.

Constata-se então, que embora os países em desenvolvimento em geral se insiram nas cadeias em atividades de baixo VA e intensivas em trabalho não qualificado, eles poderão, dependendo do padrão de atuação e de sua alteração, ampliar esses ganhos. Isso evidência a possibilidade de determinadas atuações dos países na CGV funcionarem como um mecanismo para a evolução em seus estágios produtivos, através do deslocamento de estruturas produtivas de setores de baixa intensidade tecnológica para as de alta intensidade e de maior produtividade, gerando, consequentemente, uma mudança estrutural.

É importante ressaltar que esse movimento não é automático. A simples participação nas cadeias não é condição suficiente para gerar mudanças estruturais. Além do desinteresse e dificuldades impostas pelas firmas líderes em permitir os países em desenvolvimento evoluírem no padrão de atuação e com isso, obter melhor resultado dessa inserção, são necessárias esforços específicos em termos de política econômica voltados ao processo de endogenização tecnológica, cujo assunto foge do escopo do presente artigo. Além disso, para muitos países, a inserção nas cadeias além de não ser condição suficiente, pode também nem ser condição necessária para o seu encaminhamento para estágios mais sofisticados.

Em função das diversas possibilidades de inserção e evolução nas cadeias, vê-se como importante, o mapeamento dos padrões de atuação dos países neste paradigma produtivo levando em consideração alguns aspectos referentes à mudança estrutural. Na seção a seguir, tem-se a descrição e justificativa dos indicadores selecionados neste mapeamento.

\section{INDICADORES PARA O MAPEAMENTO: DESCRIÇÃO E JUSTIFICATIVAS}

A análise da inserção e upgrading dos países nas cadeias têm sido feita frequentemente por estudos de casos individuais de países ou setores atrelados a esse paradigma produtivo. Milberg e Winkler (2013) ressaltam que estes estudos focam aspectos e períodos que se diferem muitas das vezes entre as análises, sendo que frequentemente, diferentes intensidades de variação das variáveis consideradas referindo-se a um mesmo upgrading. Essas assimetrias entre os estudos de caso tornam a sua comparabilidade difícil ou pouco eficiente para uma análise agregada de upgrading dos países nas CGV. 
Em vista dessas dificuldades e considerando-se que os diferentes padrões de atuação proporcionam diferentes resultados principalmente em termos de mudança estrutural, optou-se por fazer um mapeamento dos países nas cadeias seguindo os padrões definidos em UNCTAD (2013), referentes à: i) inserção sem nenhuma evolução; $i$ ) inserção que envolva avanços em termos de upgrading de processo e produto; e por fim, iii) inserção com avanço também em termos de upgrading de cadeia e/ou funcional. Para tal mapeamento, dada a inexistência de variáveis específicas que retratem esses tipos de upgrading, será utilizado um conjunto de indicadores que caracterizem a evolução dos países neste paradigma de forma a captar os ganhos obtidos de curto e longo prazo. Os indicadores baseiam-se em quatro tipos de dados: estatísticas tradicionais de comércio, estatísticas de comércio em termos de valor adicionado, investimento direto externo e produtividade.

\subsection{Estatísticas de Comércio em Termos Brutos: Exportações Segundo Intensidade Tecnológica}

Considerando-se as diferentes implicações dos setores sobre o crescimento do produto e da produtividade, uma composição das exportações centradas em estruturas mais intensivas em tecnologia é preferível em função da elevada elasticidade renda e o efeito transbordamento do conhecimento necessário a estas atividades para outros setores. Com base nisso, Lall (2000) faz uma classificação das exportações segundo intensidade tecnológica (exportações de produtos primários, manufaturas intensivas em recursos naturais, manufaturas intensivas em baixa, média e alta tecnologia), defendendo como um importante determinante para o upgrading, os setores intensivos em tecnologia por apresentarem elevada capacidade de learning tecnológico (STURGEON \& GEREFFI, 2009).

Baseado nessa concepção de upgrading utilizado em Lall (2000) e Sturgeon \& Gereffi (2009) e o fato de que os setores os quais a fragmentação da produção internacional tem ocorrido frequentemente são setores intensivos em média e alta tecnologia - eletrônicos e equipamentos de transporte - o presente trabalho analisará o dinamismo tecnológico das exportações a partir das estatísticas tradicionais de comércio. O primeiro indicador utilizado para o mapeamento dos padrões de atuação dos países nas CGV refere-se à variação da participação das exportações de setores manufatureiros de média e alta intensidade tecnológica nas exportações totais, entre 1995 e 2008. Para isto, utilizou-se a base de dados CONTRADE UN, nomenclatura SITC agregada em 3 dígitos.

Indicador 1: $\Delta$ Exportação de média e alta intensidade tecnológica $=\Delta\left(\operatorname{Exp}_{\mathrm{A}} / \mathrm{X}\right)$

Onde: $\Delta$ refere-se à variação; $\operatorname{Exp}_{\mathrm{A}}$ refere-se às exportações de manufaturados com média e alta intensidade tecnológica e; $\mathrm{X}$ refere-se às exportações totais.

\subsection{Estatísticas de Comércio em Termos de Valor Adicionado: Bens e Serviços}

As estatísticas de comércio quando mensuradas em termos de valor adicionado estimam a origem do valor (por país e indústria) que foi adicionado na produção voltada à exportação. Ao distinguir o VA doméstico do importado, analisa-se a influência do comércio internacional na criação de valor local e no seu potencial de criação de emprego. Fazer essa distinção num cenário de fragmentação internacional da produção é fundamental, dada a acentuada utilização de insumos importados na produção de bens finais. O cálculo desta estatística, OECD-WTO (2012), é feito a partir de uma matriz insumo-produto global oriunda da harmonização de matrizes insumo produto dos países e dos coeficientes de comércio bilaterais.

Para um melhor entendimento do comércio em termos de valor adicionado, deve-se levar em consideração que as exportações brutas dos países (X) são formadas pelo VA produzido domesticamente incorporado nas exportações de bens e serviços (VAX) e pelo valor adicionado estrangeiro ou importado $\left(\mathrm{VA}^{*} \mathrm{X}\right)$ incorporado nas exportações. Sendo que no primeiro, tem-se uma parcela utilizada na demanda doméstica de outros países $\left(\mathrm{VAX}_{\mathrm{DF}}{ }^{*}\right)$ e outra incorporada nas exportações destes $(\mathrm{VA} * \mathrm{X})$. A análise do comércio internacional nas cadeias de valor é feita com base somente no VA dos países incorporado nas exportações de terceiros, ignorando-se a parcela destinada a demanda final de outros países.

Assim, a participação de um país nas CGV é mensurada levando-se em consideração sua participação a jusante (VAX*), como criador de valor adicionado que será embutido nas exportações de outros países, e sua participação a montante (VA*X), em que utiliza VA importado nas suas exportações. $\mathrm{O}$ índice de participação nas cadeias quando expresso em relação às exportações, mostra a contribuição das exportações intra-cadeia nas exportações totais do país. Como segundo indicador para identificação 
de padrões de atuação nas cadeias referentes à inserção e o upgrading, será utilizada a variação do Índice de Participação (IP) de um país nas CGV entre 1995 e 2008, descrito amplamente em UNCTAD (2013):

Indicador 2: $\Delta \mathrm{IP}=\Delta\left[\left(\mathrm{VA}^{*} \mathrm{X}+\mathrm{VAX}^{*}\right) / \mathrm{X}\right]$

Onde: $\Delta$ refere-se à variação; IP refere-se ao Índice de Participação nas cadeias; * denota país estrangeiro e sem * país doméstico; VAX refere-se ao valor adicionado (estrangeiro/domésticas) contido nas exportações (domésticas/estrangeiras) e; X refere-se às exportações brutas.

O indicador acima é uma extensão do Índice de especialização vertical em Hummels et al (2001), em que se considerava apenas a participação via VA estrangeiro contidos na exportação - VA*X. No Índice de Participação nas CGV, capta-se também a participação de países nas CGV em etapas iniciais do processo produtivo, cuja participação ocorre predominantemente a jusante. Assim, com base neste indicador, é possível distinguir a participação nas cadeias entre importador de VA estrangeiro e exportador de VA doméstico no comércio intra-cadeia, permitindo-se com isso, analisar o resultado da inserção em termos valor adicionado líquido criado no comércio intra CGV.

Em UNCTAD (2013), o upgrading dos países nas cadeias é identificado pela participação elevada nas CGV impulsionado pelo aumento VA doméstico nas exportações (VAX*), por este contribuir positivamente para o PIB. Banga (2013) faz uma análise similar dos ganhos da inserção em termos de valor adicionado líquido. Além do grau de participação nas cadeias, a autora mensura os ganhos através da razão entre valor adicionado doméstico contido nas exportações e valor adicionado estrangeiro incorporado nas exportações $\left(\mathrm{VAX}^{*} / \mathrm{VA} * \mathrm{X}\right)$. Quando maior que um, significa que o VA doméstico criado no comércio intra Cadeias Globais de Valor superou a utilização do VA estrangeiro utilizado.

O presente trabalho, para o mapeamento da inserção e upgrading dos países, seguirá a metodologia utilizada em Banga (2013), adotando-se como terceiro indicador, a variação do saldo do valor adicionado intra-cadeia entre 1995 e 2008, medido pela razão entre VA doméstico e estrangeiro contido nas exportações no comércio intra $\mathrm{CGV}$.

\section{Indicador 3: $\Delta$ do saldo do VA intra-cadeia $=\Delta(\mathrm{VAX} * / \mathrm{VA} * \mathrm{X})$}

Onde: $\Delta$ refere-se à variação; $\mathrm{VAX}^{*}$ refere-se ao valor adicionado doméstico contido nas exportações estrangeiras e; VA*X refere-se ao valor adicionado importado nas exportações nacionais.

A restrição da análise em termos de valor adicionado líquido é que esta pode expressar que o país esteja apresentando algum upgrading, com aumento do VA doméstico nas exportações, sem a garantia de ocorrência de upgrading funcional. Isso significa que os países e firmas podem apresentar melhora em termos de produto e processo, mas sua participação no processo produtivo limitada a atividades de baixo valor adicionado ou de baixa sofisticação tecnológica. Em contrapartida, países cujos processos produtivos se deslocam para cadeias de maior sofisticação tecnológica ou para atividades e tarefas intensivas em conhecimento, pode apresentar aumento do insumo importado. Neste caso, o upgrading funcional/cadeia pode ocorrer, mesmo que o VA doméstico nas exportações esteja diminuindo.

Diante dessa limitação, optou-se em estender a análise ao setor de serviços. Essa escolha baseouse na maior capacidade de geração de valor adicionado do setor (smile curve) já discutido anteriormente. No processo produtivo de bens existe uma série de serviços que são utilizados (transporte, comunicação, TI, financeiros e etc.) e que irão agregar valor ao produto. Ao identificar o valor criado com essas atividades, vê-se exatamente o que cada setor está produzindo, seja diretamente ou indiretamente.

Assim, levando-se em consideração os aspectos ressaltados acima, uma maior participação do setor de serviços nas exportações pode configurar para o país ganhos em termos de upgrading funcional. E como as estatísticas de comércio em termos de VA permitem identificar a contribuição do setor de serviços nas exportações brutas, foram utilizados como quarto e quinto indicadores na identificação de padrões de inserção e upgrading nas cadeias, a variação da participação dos serviços (em VA) nas exportações brutas e a variação da participação do serviço doméstico (em VA) no valor adicionado total das exportações, ambos para o período entre 1995 e 2008. Esses indicadores mostram respectivamente, a importância do setor de serviços em termos de VA nas exportações dos países (seja o serviço em VA importado ou não) e a importância dos serviços domésticos no VA total doméstico nas exportações. 


\section{Indicador 4: $\Delta$ Participação do VA em serviços nas exportações brutas $=\Delta\left[\left(\mathrm{VAX}_{\mathrm{S}}+\mathrm{VA} * \mathrm{X}_{\mathrm{S}}\right) / \mathrm{X}\right]$}

Indicador 5: $\Delta$ Participação do VA doméstico em serviços no VA nas exportações $=\Delta\left(\mathrm{VAX}_{\mathrm{S}} / \mathrm{VAX}\right)$

Onde: $\Delta$ refere-se à variação; $\mathrm{VA}^{*} \mathrm{X}_{\mathrm{S}}$ refere-se ao valor adicionado estrangeiro em serviços contido nas exportações; $\mathrm{VAX}_{\mathrm{S}}$ refere-se ao valor adicionado doméstico em serviços contido nas exportações; $\mathrm{VAX}_{\mathrm{S}}+\mathrm{VA} * \mathrm{X}_{\mathrm{S}}$ refere-se à contribuição do serviço em VA nas exportações brutas; VAX refere-se ao valor adicionado doméstico nas exportações.

Ainda analisando o setor de serviços como forma de avaliar a importância de atividades de maior geração de VA na economia e até mesmo a ocorrência de upgrading funcional dos países, outro aspecto a ser considerado refere-se ao fato de que diferentes tipos de serviços apresentam diferentes capacidades de gerar valor adicionado, sendo o potencial de criação de VA relacionado à intensidade da qualificação da mão de obra necessária em cada etapa. Diante disso, optou-se por desagregar o indicador 5 de serviços em alguns segmentos específicos, de forma a identificar se as atividades de serviços mais intensivas em conhecimento variaram nas exportações dos países após a inserção nas CGV. Para isto, considerou-se a classificação utilizada pela agência estatística "Eurostat", em que classifica os serviços segundo intensidade de conhecimento a partir da classificação NACE (Statistical Classification of Economic Activities in the European Comunity) das atividades econômicas. A agência desagrega os serviços não financeiros em "serviços pouco intensivos em conhecimento", "serviços de mercado intensivos em conhecimento" e "serviços high-tech intensivos em conhecimento",

Assim, baseado nessa classificação e levando-se em consideração o baixo nível de desagregação setorial da base de dados TIVA (18 setores), foi utilizado como sexto indicador na análise de inserção e upgrading dos países nas $\mathrm{CGV}$, a variação do VA doméstico dos serviços de: "transporte, armazenamento, correio e telecomunicações"; "intermediação financeira" e; "serviços de negócios".

Indicador 6: $\Delta$ Participação do VA doméstico em serviços ${ }_{a, b, c}$ no VA doméstico nas

$$
\text { exportações }=\Delta\left(\mathrm{VAX}_{\mathrm{S} \text { a,b,c }} / \mathrm{VAX}\right)
$$

Onde: $\Delta$ refere-se à variação; $\mathrm{VAX}_{\mathrm{Sa}, \mathrm{b}, \mathrm{c}}$ ao valor adicionado doméstico em serviços $a, b$, e $c$ contido nas exportações, sendo (a) transporte, armazenamento, correio e telecomunicações; (b) intermediação financeira e; (c) serviços de negócios; VAX refere-se ao VA doméstico nas exportações.

Para o cálculo de todos os indicadores em termos de valor adicionado desta seção, foi utilizada a base de dados OECD-WTO Trade in Value-Added (TIVA) - Maio 2013, que mostra informações em termos de valor adicionado para 58 economias em 18 setores (classificação STAN. rev.3).

\subsection{Investimento Direto Externo (IDE)}

A fragmentação internacional da produção foi um movimento iniciado pelas grandes corporações nos anos 80 em busca de redução dos seus custos de produção em um ambiente regulatório de maior liberalização financeira e comercial. Segundo UNCTAD (2013), o Investimento Direto Externo teve um papel fundamental neste processo, confirmado pela forte correlação entre esse tipo de investimento e a participação dos países nas CGV. A partir de algumas estimações, este estudo verificou que para muitos países, quanto maior a importância do IDE em relação ao tamanho da economia, maior a participação nas cadeias e maior o valor adicionado nas exportações.

No entanto, Baldwin (2012) e UNIDO (2013) ressaltam o baixo potencial de learning tecnológico das atividades inerentes ao IDE sob o paradigma das CGV. Até os anos 80, a transferência tecnológica envolvia investimento direto externo ou licenciamento, que através de parcerias ou mesmo imitação, os países construíam capacitações para a aplicação ou modificação da tecnologia estrangeira utilizada. Recentemente, a transferência via redes de produção ocorre geralmente sob a forma de "tecnologia emprestada" com firmas internacionais provendo sua tecnologia a ser utilizada, mas que é altamente protegida por direitos de propriedade, dificultando ou impedindo com isso, o transbordamento do

\footnotetext{
${ }^{4}$ Serviços high-tech intensivos em conhecimento: correios e telecomunicações, informática e atividades relacionadas; $\underline{\text { Serviços }}$ de mercado intensivos em conhecimento; transporte aéreo e marítimo e outras atividades de negócio; Serviços pouco intensivo em conhecimento: de comércio, hotéis e restaurantes, transporte terrestre e outras atividade auxiliares de transporte. (http://epp.eurostat.ec.europa.eu/statistics_explained/index.php_High-tech_statistics).
} 
conhecimento do setor para o restante da economia. Em vista desses efeitos contraditórios, interpreta-se o padrão de inserção dos países nos fluxos internacionais de IDE como mais um elemento considerado na caracterização da inserção e evolução dos países nas CGV.

Assim, no sétimo e no oitavo indicador são calculados o saldo líquido do IDE como percentual do PIB em 2008 e a sua variação entre 1995 e 2008, mostrando-se com isso, a direção e a intensidade desse padrão de relação do país com o investimento direto externo. Visa-se com esses indicadores, identificar se a maior participação nas cadeias ocorreu com o aumento do influxo do IDE, e principalmente se influenciou o resultado em termos de mudança estrutural. Sobre o cálculo do saldo líquido, optou-se pela diferença entre saída e entrada de capital por querer analisar se o upgrading nas CGV permite diminuir a dependência do capital externo ao longo do tempo. Ressalta-se que em função da volatilidade desses fluxos, o saldo é calculado a partir da média dos três anos finais e iniciais.

Indicador 7: IDE líquido = (fluxo de saída - fluxo de entrada $) /$ PIB

$\underline{\text { Indicador 8: }} \Delta \mathrm{IDE}$ líquido $=\Delta[$ (fluxo de saída - fluxo de entrada $) / \mathrm{PIB}]$

Além desses dois indicadores, será analisado o grau de integração do país aos mercados internacionais através da variação do Índice de intensidade do $\operatorname{IDE}^{5}$ para o mesmo período, indicador nono, que se refere à média dos fluxos de entrada e saída do investimento direto externo, também como percentual do PIB. Para o cálculo dos indicadores 7, 8 e 9, é utilizada a base de dados da UNCTAD ${ }^{6}$.

Indicador 9: $\Delta$ Intensidade do IDE $=\Delta[(($ fluxo de saída + fluxo de entrada $) / 2) / P I B]$

\subsection{Produtividade do Trabalho e Mudança Estrutural}

A inserção dos países em desenvolvimento nas cadeias, além de favorecer a criação de emprego e produto, tem contribuído para muitos, na alteração de suas estruturas produtivas e de exportação, em direção a produtos manufaturados com maior conteúdo tecnológico e com maior potencial de crescimento de produtividade do setor e da economia. No entanto, essa industrialização é frequentemente superficial, dada a transferência somente de etapas pouco intensivas em conhecimento, dificultando ou impossibilitando a endogenização tecnológica. Nesse sentido, a mudança estrutural ocorrida é restrita, com o processo de acumulação de capital e incorporação do progresso técnico não sendo sustentável no longo prazo, uma vez que a sustentação dos ganhos da inserção ao longo do tempo requer uma evolução dos países nessas cadeias sob a forma de upgrading funcional e/ou de cadeia, possibilitando também avanços em seus estágios produtivos.

Diante dos aspectos referentes aos ganhos de longo prazo, reconheceu-se como importante, avaliar o quanto a participação nas CGV tem sido acompanhada pelo crescimento da produtividade destas economias, cuja variável está correlacionada ao processo de acumulação de capital e incorporação do progresso técnico. Assim, para o mapeamento dos padrões de inserção e evolução dos países nas cadeias, utilizou-se como décimo indicador a variação da produtividade do trabalho [OCDE (2013)].

\section{Indicador 10: $\Delta$ Produtividade $=\Delta(\mathrm{Y} / \mathrm{L})$}

Onde: $\Delta$ refere-se à variação; Y refere-se à produção em VA e; L ao número de trabalhadores.

Deve-se ressaltar que a variação da produtividade é impulsionada por dois componentes: um derivado de mudanças intra-setoriais e outro derivado de realocações entre os setores. MacMillan e Rodrick (2011) e Kucera e Roncolato (2012) descrevem o primeiro componente como decorrente do processo de acumulação do capital, incorporação do progresso técnico e da melhor alocação dos fatores dentro do setor, enquanto o segundo, resultado do deslocamento dos trabalhadores de setores de baixa produtividade para os de alta produtividade, ambos contribuindo para o aumento da produtividade agregada. A distinção destes dois elementos na variação da produtividade permite, segundo os autores, identificar a ocorrência ou não de mudança estrutural na economia. Essa é captada por meio do componente de realocação da mão-de-obra entre os setores, que mostrará se a nova composição ocorreu em direção a setores de maior ou menor produtividade.

\footnotetext{
${ }^{5}$ Índice calculado pela Eurostat: http://ec.europa.eu/eurostat/en/web/products-datasets/-/TEC00124 visto em 10/01/2015.

${ }^{6}$ UNCTAD: http://unctadstat.unctad.org/wds/ReportFolders/reportFolders.aspx visto em 12/12/2014.
} 
Assim, para análise dos ganhos de longo prazo obtidos com a participação nas cadeias, será utilizado como décimo primeiro indicador, o componente realocação inter-setorial da variação da produtividade. Além disso, optou-se por considerar também a participação desse componente de mudança estrutural na produtividade, sendo utilizado como décimo segundo indicador, a razão entre o indicador 11 e 10. Em Kucera e Roncolato (2012) são calculados a variação da produtividade agregada entre 1999 e 2008 e também a sua decomposição nos elementos intra-setorial e inter-setorial para o mesmo período. Optou-se por utilizar os dados calculados neste trabalho para os indicadores 10, 11 e 12.

\section{Indicador 11: Componente realocação entre setores da produtividade - mudança estrutural}

\section{Indicador 12: Participação do componente realocação entre setores na variação da produtividade}

Os doze indicadores foram calculados para 40 países, selecionados com base na disponibilidade de dados (principalmente da estatística de comércio em termos de VA) e nas características gerais dos países. Com exceção do indicador 7 de saldo líquido do IDE, os indicadores são de variação, de forma a identificar a evolução dos países nessa dinâmica. Ressalta-se ainda que os indicadores de produtividade e mudança estrutural referem-se ao período entre 1999 e 2008. A tabela 1 em anexo resume o resultado de todos os indicadores.

\section{DESCRIÇÃO DOS RESULTADOS: INDICADORES ISOLADOS E CONJUNTOS}

Com uma análise dos indicadores isolados, constataram-se algumas evidências referentes às CGV. A primeira refere-se ao índice de participação dos países nas cadeias. Observou-se que os com maior índice de participação em 2008, são países pequenos que dependem fortemente de insumos importados e que a demanda externa atua como mercado consumidor importante para a sua produção. Ressalta-se ainda, que desses países que mais cresceram nas cadeias globais, poucos o fizeram via serviços.

Outro aspecto identificado refere-se ao saldo em VA do comércio intra-cadeia. Foi discutida a importância da participação nas cadeias em etapas à jusante $\left(\mathrm{VAX}^{*}\right)$ por contribuir positivamente para a geração de renda e emprego local, com o seu aumento relativo associado ao upgrading dos países nas CGV. Observou-se, no entanto, que a maior participação dos países nas cadeias também ocorreu com aumento relativo do VA importado. O indicador de variação do VA líquido intra-cadeia mostrou praticamente a metade dos países da amostra reduzindo este indicador, e muitos deles países desenvolvidos. Com isso, desvincula-se a ideia de que saldo negativo de VA intra-cadeia esteja somente associado a países com alta atuação nas cadeias em etapas de montagem e processamento, enfraquecendo também o entendimento de variação positiva do saldo do VA intra-cadeia como upgrading dos países dentro das cadeias. UNCTAD (2013) oferece algum indicativo sobre isto ao defender que este pode ocorrer não exclusivamente via aumento do VA doméstico, entretanto, a ocorrência frequente da variação negativa deste saldo entre os diferentes países - incluindo os desenvolvidos, que a literatura interpreta como os que galgaram positivamente nas cadeias ao se concentrarem em atividades intensivas em tecnologia e conhecimento - mostra que a estatística está longe de captar totalmente o upgrading.

A respeito da importância do setor de serviços em termos de criação de valor adicionado e a tentativa de se identificar a ocorrência de upgrading funcional, percebe-se que os países que apresentaram redução do saldo de VA intra-cadeia, apenas alguns - principalmente os desenvolvidos - conseguiram amenizar essa variação aumentando o valor adicionado em serviços.

$\mathrm{Na}$ identificação do padrão de inserção dos países no fluxo de investimento direto, observam-se os países mais integrados internacionalmente, e sobre o padrão dessa integração, quase todos os que apresentaram saldo líquido positivo do IDE em 2008, aumentaram o envio do IDE para outros lugares e são, em geral, países desenvolvidos. Já entre os países que apresentaram saldo líquido negativo característico dos países em desenvolvimento - a variação desse saldo negativo foi bem heterogênea não se identificando uma relação direta entre evolução nas cadeias e grau de dependência ao IDE.

Quanto à produtividade, constatou-se que a maioria dos países da amostra apresentou aumento no período, sendo que no componente inter-setorial desse indicador, utilizado como proxy de mudança estrutural, identificaram-se diferentes dinâmicas referentes a essas variáveis e à evolução nas CGV.

Com os indicadores isolados, foram evidenciadas algumas tendências referentes às CGV. Entretanto, para o mapeamento dos países nas cadeias, optou-se por considerar simultaneamente alguns 
aspectos recorrentes neste processo através de uma análise conjunta dos indicadores. Diante da disponibilidade de uma grande quantidade de informações, foi utilizada a técnica de agrupamento ou clusters, de forma a identificar padrões entre os países da amostra.

Segundo Johnson e Wichern (2007), a técnica de agrupamento consiste na criação de grupos para elementos da amostra com características similares. Para isto, utilizam-se medidas de distância que definirão a similaridade ou dissimilaridade entre esses elementos. Quando não se sabe a priori o número de grupos a serem criados, estes se formam hierarquicamente, com os elementos se reunindo por etapa, respeitando alguma regra de aglomeração. Com isso, criam-se grupos cada vez maiores, mas em menor quantidade, sendo a escolha dessa quantidade a critério do usuário que deve basear-se nas características a serem priorizadas. À medida que os grupos crescem, a homogeneidade entre os elementos dos grupos diminui, cabendo ao pesquisador a decisão quanto à perda de informação. Ressalta-se que os grupos formados com a técnica de cluster pode não ter respaldo teórico - agrupamentos em função de similaridades empíricas e sem defesa de causalidade entre as variáveis - e por isso, a importância da aplicação de diferentes técnicas aglomerativas de forma a se obter o resultado mais frequente.

No presente trabalho, os clusters foram calculados através do software estatístico SPSS, para os 40 países da amostra e os 12 indicadores, utilizando-se diferentes técnicas. Previamente, fez-se uma categorização dos resultados dos indicadores, convertendo-os para quatro valores representando níveis de intensidade ${ }^{7}$. A opção pela categorização baseou-se no objetivo do trabalho de mapear a evolução dos países nas cadeias, de forma a identificar intensidades de desempenho neste paradigma produtivo, sendo irrelevante pequenas diferenças nas variações. Além disso, ressalta-se que como a escolha do número de grupos fica a critério do usuário da técnica, buscou-se à medida que os grupos foram se formando, respeitar alguns padrões comuns referentes a determinadas variáveis de desempenho nas cadeias ${ }^{8}$.

Com o resultado da técnica utilizada, identificaram-se seis padrões de atuação no que diz respeito à inserção e evolução nas cadeias, com algumas características importantes que os distinguem uns dos outros. A tabela 1 resume a composição de cada grupo e as respectivas características em termos de indicadores que os diferem uns dos outros. Os grupos gerados foram distribuídos nas colunas, ordenandose os países de acordo com a intensidade da variação da participação nas cadeias (indicador 2). Os países expressos em itálico foram os que tiveram baixo crescimento ou redução da participação nas cadeias globais e que serão excluídos da análise. A respeito dos termos "baixíssimo, baixo, médio e alto", estes se referem aos intervalos criados com a categorização ${ }^{9}$. Além disso, utilizou-se (----) quando não se identificou um padrão do indicador entre os países do mesmo grupo. As notas de rodapé na tabela referem-se às exceções às regras, com algum país não se encaixando no padrão identificado. Na tabela 2 em anexo encontram-se os dados (categorizados) organizados de acordo com os grupos gerados. de serviços

- Grupo 1: países desenvolvidos com padrão de IDE de países desenvolvidos e expansão do setor

O grupo 1 é formado por países desenvolvidos tendo como característica principal, um padrão de fluxo de IDE comum dos países desenvolvidos de saldo líquido positivo - fluxo de saída menos entrada e crescimento desse saldo. Em paralelo, observou-se um crescimento da participação dos serviços em VA nas exportações dos países. Ressalta-se ainda o fato dos países apresentarem ou baixo crescimento da produtividade (em alguns casos, redução), mas impulsionada pelo componente mudança estrutural, ou então, variação média da produtividade concomitantemente à baixa mudança estrutural. A exceção a essa regra foi a Coreia, apresentando simultaneamente níveis mais altos para os dois indicadores, e Japão e Alemanha, para o indicador de mudança estrutural. Não se identificou um padrão comum na intensidade

\footnotetext{
${ }^{7}$ Os intervalos foram definidos de acordo com a frequência dos países nos níveis, cujos limites foram determinados de forma que cada um contivesse aproximadamente $1 / 4$ dos países da amostra. As categorias criadas referem-se, em geral, à variação negativa, baixa, média e alta.

${ }^{8}$ As variáveis priorizadas foram: variação do saldo do VA intra-cadeia - pelo potencial de criação local de renda e emprego; variação da participação do setor de serviços - para a caracterização do upgrading funcional; variação do IDE líquido - pela importância do IDE neste paradigma produtivo; e por fim, mudança estrutural - que é o objetivo do trabalho.

${ }^{9} \mathrm{Na}$ maioria dos indicadores, o primeiro intervalo refere-se à variação negativa, sendo classificado como negativo. Entretanto, nos indicadores de variação do índice de participação e da produtividade, o primeiro intervalo refere-se à variação negativa mais também abrangendo países com variação positiva em níveis bem baixos, neste caso, sendo classificado como baixíssimo.
} 
de variação da participação nas cadeias desses países: alguns apresentaram crescimento elevado (como Japão, Coreia e Irlanda), outros, crescimento mediano, paralelamente a alguns países com crescimento bem baixo. Ao separar estes países com baixíssimo avanço nas cadeias (Bélgica, Holanda, Espanha, Itália e Reino Unido), observou-se que os que mais aumentaram a participação nas cadeias, apresentaram também redução do saldo do VA intra-cadeia e níveis mais elevados de mudança estrutural. Além disso, a variação das exportações de manufaturas intensivas em tecnologia ocorreu nos três níveis mais baixos.

Tabela 1 - Mapeamento da inserção e evolução dos países nas CGV e a mudança estrutural.

\begin{tabular}{|c|c|c|c|c|c|c|}
\hline & Grupo 1 & Grupo 2 & Grupo 3 & Grupo 4 & Grupo 5 & Grupo 6 \\
\hline & $\begin{array}{c}\text { Japão } \\
\text { Coreia } \\
\text { Irlanda } \\
\text { Áustria } \\
\text { Alemanha } \\
\text { França } \\
\text { EUA } \\
\text { Bélgica } \\
\text { Holanda } \\
\text { Espanha } \\
\text { Itália } \\
\text { Reino Unido }\end{array}$ & $\begin{array}{l}\text { Filipinas } \\
\text { Malásia }\end{array}$ & $\begin{array}{c}\text { Índia } \\
\text { Taiwan } \\
\text { Polônia } \\
\text { Cingapura } \\
\text { Romênia } \\
\text { Hong Kong } \\
\text { Bulgária } \\
\text { Canadá } \\
\text { Camboja }\end{array}$ & $\begin{array}{c}\text { China } \\
\text { Vietnã } \\
\text { Turquia } \\
\text { Tailândia } \\
\text { Indonésia }\end{array}$ & $\begin{array}{c}\text { Hungria } \\
\text { República } \\
\text { Checa } \\
\text { Eslováquia }\end{array}$ & $\begin{array}{c}\text { Chile } \\
\text { Rússia } \\
\text { Portugal } \\
\text { Austrália } \\
\text { Brasil } \\
\text { México } \\
\text { Israel } \\
\text { África do Sul } \\
\text { Argentina }\end{array}$ \\
\hline IDE & $>0$ & $>0$ & $<0^{3}$ & $<0$ & $<0$ & $<0$ \\
\hline$\Delta \mathrm{IDE}$ & $>0$ & $>0$ & $<0$ & ----- & ----- & ----- \\
\hline$\Delta \mathbf{I P}$ & ---- & $\begin{array}{c}>0 \\
\text { (médio/alto) }\end{array}$ & ---- & $\begin{array}{c}>0 \\
\text { (médio/alto) }\end{array}$ & $\begin{array}{c}>0 \\
\text { (médio/alto) }\end{array}$ & ----- \\
\hline$\Delta \mathbf{V A X}$ & ----- & $>0$ & ---- & ---- & $<0$ & $>0$ \\
\hline$\Delta \mathbf{V A X s}$ & $>0$ & $<0$ & $>0$ & $<0$ & $<0$ & ----- \\
\hline$\Delta$ Ptde & $\begin{array}{l}\text { baixíssimo/ } \\
\text { baixo }^{1}\end{array}$ & médio & médio/alto & médio/alto & médio/alto & $\begin{array}{l}\text { baixíssimo/ } \\
\text { baixo }^{6}\end{array}$ \\
\hline ME & $\begin{array}{l}\text { baixíssimo/ } \\
\text { baixo }^{2}\end{array}$ & $=0$ & médio/alto ${ }^{4}$ & alto & $\begin{array}{l}\text { baixíssimo/ } \\
\text { médio }\end{array}$ & baixo/médio ${ }^{6}$ \\
\hline$\Delta \mathbf{E x p}$ & ---- & ----- & ----- & $\begin{array}{c}>0 \\
\text { (médio/alto }^{5} \text { ) }\end{array}$ & $\begin{array}{c}>0 \\
\text { (alto) }\end{array}$ & ----- \\
\hline
\end{tabular}

Fonte: elaboração própria. Legenda: $\Delta$ (variação); IDE (saldo do Investimento Direto Externo); IP (índice de participação nas CGV); VAX (saldo do valor adicionado intra-cadeia); VAXs (VA de serviços no VA doméstico das exportações); Ptde (produtividade); ME (mudança estrutural); Exp (exportações).

Notas: 1. Coreia - alta; 2. Coreia, Japão e Alemanha - ME elevada; 3. Taiwan - positivo; 4. Bulgária - negativa; 5.Tailândia redução; 6. Rússia - produtividade elevada e ME negativa.

Em linhas gerais, os países desse grupo são as economias que no período apresentaram trajetórias de crescimento mais estabilizadas. $\mathrm{O}$ aprofundamento da participação nas cadeias desses países, com exceção do Japão, Coreia e Irlanda, não foi tão expressivo em termos de participação nas exportações. Entretanto, ressalta-se que essa evolução se deu pela expansão dos setores de serviços, confirmando o fato de que as grandes corporações situadas principalmente nos países desenvolvidos deslocaram as etapas manufatureiras intensivas em trabalho para os países abundantes deste fator. E novamente ressalta-se, que os países que aumentaram suas participações, o fizeram reduzindo o saldo de VA intra-cadeia, mesmo sendo os países que avançaram em termos de serviços. A prova de que analisar o upgrading dos países nas cadeias através deste indicador é insuficiente, principalmente se estivermos falando de upgrading funcional. E sobre a Coreia e o Japão, que são os países com níveis mais altos de crescimento da participação nas cadeias não só do grupo mas de toda a amostra, foram também os países em que o componente mudança estrutural teve um peso relevante na variação da produtividade neste grupo.

O crescimento da participação desses países nas cadeias em paralelo ao crescimento da importância dos serviços nas exportações em VA e a mudança estrutural em nível médio/elevado sugerem entre esses países, a existência de um padrão de atuação com evolução em termos principalmente de upgrading funcional. A redução ou baixo crescimento das exportações de alta intensidade tecnológica não indica a ocorrência de upgrading de cadeia, ou então, ele já ocorrendo em etapas mais sofisticadas. 
- Grupo 2: países subdesenvolvidos com padrão de IDE de países desenvolvidos e com retração do setor de serviços e expansão de setores manufatureiros

O grupo 2, Filipinas e Malásia, tem como característica marcante um padrão de IDE similar ao países desenvolvidos do grupo 1, entretanto, apresentando redução da participação do VA de serviços nas exportações. Além de crescimento do saldo do valor adicionado intra-cadeia, identificou-se o aumento da produtividade destes países superior ao primeiro grupo, mas com o componente mudança estrutural nulo. Além disso, esses países apresentaram crescimento da participação nas cadeias significativo. Sobre as exportações de manufaturas de alta intensidade tecnológica, não houve uniformidade no grupo: na Malásia houve redução dessas exportações enquanto em Filipinas crescimento em nível elevado.

Numa análise setorial desses países - desagregação setorial da base de dados TIVA-OCDE versão maio de 2013 -, a composição das exportações em 2008 (tabela 3 em anexo) dá sinais do porquê do componente mudança estrutural ser nulo, embora por motivos diferentes entre os dois países. Os dados mostram que em Filipinas, desde 95, houve um crescimento abrupto do setor de equipamento "eletrônicos e elétricos", com o segmento assumindo $65 \%$ das exportações, sendo o setor "driver" na maior inserção do país nas cadeias. Já na Malásia, quase não houve alteração da composição de suas exportações. Com isso, identifica-se que a inexistência de mudança estrutural na Malásia foi decorrente de fato da rigidez da composição setorial do país, mas que em Filipinas, foi devido à forte concentração em um segmento à custa da redução de vários outros, inclusive de setores mais produtivos. Com a inserção nas CGV, o país se tornou uma plataforma de exportação de tais produtos.

Em linhas gerais, pode-se dizer que são países que desde 95 vem ampliando bastante a participação nas cadeias - em 2008 já se encontravam dentre os países com maior nível deste indicador -, chamando atenção a menor dependência ao investimento externo nesta atuação e também da maior captura de VA doméstico intra-cadeia. A respeito do padrão de atuação desses países, dado o crescimento acentuado da participação nas cadeias, com a produtividade destes países crescendo em patamar de nível médio paralelamente a mudança estrutural nula, interpreta-se a evolução nas cadeias em termos de eficiência produtiva ou mesmo de agregação de valor sobre o produto, característicos do upgrading de processo e produto ou então, um lock-in posterior a algum avanço prévio nas cadeias. Em Filipinas, a mudança estrutural zero associado ao crescimento abrupto das exportações intensivas em tecnologia pode referir-se a um aprisionamento posterior a um upgrading de cadeia, em que a concentração em atividades pouco intensivas em conhecimento gera efeitos de transbordamento para o restante da economia limitados, enquanto na Malásia, uma estrutura das exportações totalmente rígida no período, e também com a mesma limitação quanto ao efeito da atuação nas cadeias sobre o restante da economia.

Os grupos a seguir têm como característica distinta aos anteriores, o padrão de fluxo de IDE comum aos países subdesenvolvidos, de saldo líquido negativo.

- Grupo 3: países em desenvolvimento com avanço nas cadeias nos setores de serviços

O grupo 3 é composto por um misto de países europeus e asiáticos - Índia, Taiwan, Polônia, Cingapura, Hong Kong.... - apresentando paralelamente ao fluxo de entrada de IDE superior a saída, piora desse saldo negativo entre 95 e 2008. Simultaneamente, o grupo caracteriza-se pelo crescimento da importância dos setores de serviços em suas economias, identificado pelo aumento do VA em serviços embutido nas exportações. Esses países também apresentaram crescimento médio/alto da produtividade, principalmente o componente mudança estrutural, também em nível médio/alto. Sobre o saldo do VA intra-cadeia, não houve uniformidade entre os países, com metade apresentando aumento e outra metade, redução. Além disso, não houve homogeneidade entre os países na variação da participação das cadeias, ressaltando que Camboja e Canadá, apresentaram níveis baixíssimos de crescimento nesse indicador, sendo com isso, excluídos da análise.

Em linhas gerais, pode-se dizer que esses países apresentam grande participação nas cadeias de valor em paralelo a um padrão de dependência crescente ao IDE. Ademais, identificam-se os mesmos tanto avançando no setor de serviços quanto em termos de produtividade e mudança estrutural. Com esses dados pode-se pensar em ganhos referentes ao upgrading de produto e processo, mas principalmente numa evolução nas cadeias de valor em termos de upgrading funcional e também em termos de cadeia. $\mathrm{O}$ funcional por alguns países deste grupo estar entre os com maior crescimento dos serviços em VA nas exportações, inclusive em serviços intensivos em conhecimento, e o de cadeia, em função do resultado 
anterior também ter sido acompanhado do aumento das exportações de alta intensidade tecnológica e do saldo de valor adicionado intra-cadeia.

\section{-Grupo 4: países em desenvolvimento com avanço nas cadeias em outros setores e com alta mudança estrutural}

O grupo 4 compostos pela China, Indonésia, Tailândia, Turquia e Vietnã, apresenta saldo do IDE negativo com a variação desse saldo distinguindo-se entre os países. Esse grupo se caracteriza pelo crescimento médio/alto na participação nas cadeias globais principalmente em setores manufatureiros, com o VA de serviços nas exportações reduzindo-se. Simultaneamente a isto, identificou-se como característica importante do grupo, um padrão de crescimento médio/alto da produtividade, impulsionado em grande parte pelo componente de realocação da mão-de-obra entre os setores, o que caracteriza uma acentuada mudança estrutural nessas economias. Ressalta-se ainda que estes países, exceto Tailândia, apresentaram crescimento médio/alto das exportações de manufaturas de alta intensidade tecnológica. Não se identificou no grupo, um padrão referente à variação do saldo do valor adicionado intra-cadeia.

Em linhas gerais, pode-se dizer que os países desse grupo têm ampliado muito sua participação nas cadeias principalmente em segmentos manufatureiros simultaneamente ao crescimento da produtividade e de mudanças estruturais. O aumento dos dois primeiros sugere a ocorrência de upgrading de produto e processo, enquanto o elevado componente de mudança estrutural associado ao aumento das exportações de alta intensidade tecnológica (com exceção da Tailândia, que reduziu), sugere o upgrading de cadeia, cuja atuação para cadeias mais sofisticadas contribui para o avanço em seus processos de industrialização. Já na Tailândia, em função da redução das exportações de alta intensidade tecnológica, sugere-se que este upgrading já pode ter ocorrido previamente, e agora o país já apresente alguma evolução em termos de upgrading funcional.

Uma análise mais detalhada da composição das exportações - desagregação setorial da base de dados TIVA-OCDE versão maio de 2013, tabela 3 em anexo -, indica que a participação desses países nas cadeias tem atuado como um upgrading industrial. Os setores alimentícios e têxteis se destacam em suas pautas de exportação, mas observando-se mudança desse padrão, com a importância crescente de setores intensivos em tecnologia como equipamentos eletrônicos e de transporte.

\section{- Grupo 5: países em desenvolvimento com avanço nas cadeias em outros setores e com baixa mudança estrutural}

O grupo 5 - Hungria, República Checa e Eslováquia - apresentou um comportamento similar ao grupo 4, diferenciando-se apenas quanto às características referentes à mudança estrutural. Assim, repetindo-se o padrão de IDE, de participação nas cadeias, redução dos serviços e aumento significativo da produtividade, o grupo 5 diferencia-se do anterior pelos níveis mais baixo de mudança estrutural, sendo em alguns casos, negativo. Dois aspectos adicionais a ser ressaltados no grupo, referem-se ao fato de apresentarem redução do VA intra-cadeia (no grupo anterior este indicador não foi homogêneo) e o crescimento elevado das exportações intensivas em tecnologia em todos os países.

Em geral, pode-se dizer que esse grupo é formado por países que vem crescendo a participação nas cadeias em atividades manufatureiras em paralelo ao elevado crescimento da produtividade, entretanto, não impulsionado pelo componente inter-setorial do indicador. Com isso, observa-se uma rigidez da composição estrutural desses países ou até mesmo uma mudança estrutural negativa com maior participação de setores menos eficientes. Esse fato acompanhado da redução do saldo do VA intra-cadeia e do aumento significativo das exportações de alta intensidade tecnológica sugere a concentração em atividades de montagem e processamento. Uma análise mais detalhada da composição das exportações destes países - desagregação setorial da base de dados TIVA-OCDE versão maio de 2013, tabela 3 e 4 em anexo, serve como elemento adicional para sugerir a especialização nessas atividades de baixo VA, com crescimento dos setores de equipamentos de eletrônicos e principalmente de transporte (os dois mais relevantes no paradigma de fragmentação internacional da produção), as custas de outros setores, inclusive de serviços, o que mostra uma pequena alteração da estrutura produtiva em direção setores menos produtivos, diferente do que ocorreu no grupo 4. Conclui-se, que apesar da maior participação nas cadeias, pouco se vê em termos de evolução, restringindo-se no geral ao upgrading de produto e processo. 


\section{- Grupo 6: países em desenvolvimento com pouco avanço nas cadeias, ganhos de produtividade médio e com baixa mudança estrutural.}

E por fim o grupo 6, composto pela África do Sul, Argentina, Austrália, Brasil, Chile, Israel, México, Portugal e Rússia. Esses países além de apresentarem padrão de IDE dos grupos 4 em diante, o grupo se caracteriza no geral pelo crescimento em níveis baixos da participação nas cadeias globais (com exceção do Chile, em nível elevado), paralelamente a um aumento significativo pela maioria do saldo do VA intra-cadeia. Sobre este último, ressalta-se que esses são os países (de toda a amostra) cujo saldo do VA intra-cadeia em 2008 foi muito superior a 1. Além disso, apresentaram baixo crescimento da produtividade, embora com participação relevante do componente de realocação da mão-de-obra entre os setores neste indicador, o que caracteriza mudança estrutural média nessas economias. A maioria dos países também apresentou redução do setor de serviços nas exportações, com exceção de alguns que apresentaram alguma evolução no segmento, mas com o setor tendo pouca relevância nas exportações.

Em linhas gerais, vê-se que este grupo é formado por países que atuam em atividades intensivas em recursos naturais no início da cadeia. Como a participação nas cadeias ocorre predominantemente em etapas a jusante $\left(\mathrm{VAX}^{*}\right)$, dado a baixa necessidade de importar insumos para estas atividades, o índice de participação é mais baixo e o saldo do valor adicionado intra-cadeia elevado. Ressalta-se ainda, que o México, apesar de atuar em atividades de montagem e processamento de baixo valor adicionado nas indústrias maquilas e com isso uma participação significativa nas cadeias de valor à montante (VA*X), também é um grande exportador de recursos naturais. E sobre o primeiro tipo de atividade desempenhada, grande parte das exportações destas indústrias são destinadas aos Estados Unidos como demanda final, não sendo neste caso, contabilizado como comércio intra-cadeia, mas captado pela elevada variação das exportações de manufaturas de média e alta intensidade tecnológica. Uma análise mais detalhada da composição das exportações dos países do grupo - desagregação setorial da base de dados TIVA-OCDE versão maio de 2013, tabela 4 em anexo -, confirma a especialização em setores intensivos em recursos naturais e os referentes às indústrias maquilas.

Pelas características comuns captadas entre esses países, observa-se uma participação mais baixa nas cadeias que combinado a um baixo crescimento da produtividade (embora com predomínio do componente de mudança estrutural), sugere-se baixa alteração do padrão de atuação ou mesmo, uma evolução apenas em termos de upgrading de produto e processo. Embora o indicador de variação do saldo do valor adicionado indique a ocorrência de upgrading desses países nas cadeias, a etapa o qual atuam principalmente associado ao baixo desempenho em termos de produtividade e mudança estrutural, desconstrói esse pensamento. E a respeito de Israel, este não se encaixa nas justificativas dadas ao grupo, sendo necessário para a fundamentação de suas características, um estudo mais detalhado sobre o país.

O mapeamento do padrão de atuação dos países nas CGV permitiu identificar algumas características inerentes a participação nesse paradigma de produção, e com isso, potencialidades de ganhos obtidos, e também caminhos percorridos em termos de upgrading. Assim, com o intuito de obter relações entre atuação nas cadeias e mudança estrutural, as características que justificam o padrão de atuação dos seis grupos identificados foram resumidas na tabela 2. Ressalta-se ainda, que não foi identificado nenhum padrão entre os indicadores de IDE, o de participação nas cadeias e o de mudança estrutural. Sendo assim, os indicadores de investimento direto serviram apenas para mapear o padrão de integração dos países a esses fluxos em paralelo a maior participação nas cadeias, sem caracterizar nenhum tipo de evolução dos países nas cadeias, e, portanto, excluídos da tabela a seguir.

Com base nos resultados listados, verificou-se que os países que tiveram crescimento elevado na participação nas cadeias simultaneamente a elevada mudança estrutural apresentaram dois padrões de comportamento entre os indicadores.

O primeiro refere-se aos países que avançaram em termos de participação dos serviços nas exportações, principalmente serviços intensivos em conhecimento, e diminuíram as exportações intensivas em tecnologia. Além disso, grande parte desses países tiveram redução do saldo valor adicionado intra-cadeia. Com esses dados, interpretou-se como sendo os países cujo padrão de atuação nas CGV abrange também evolução em termos de upgrading funcional, o que contribuiu para o avanço dos mesmos em seus estágios produtivos em direção a estruturas mais desenvolvidas. Esse padrão de atuação ocorreu nos países dos grupos 1 e 3 . O grupo 1, de países desenvolvidos, onde estão sediadas no 
geral as grandes corporações que iniciaram o processo de fragmentação internacional da produção, cujas empresas concentraram-se em atividades referentes à pesquisa, desenvolvimento do produto e detenção da marca. Enquanto no grupo 3, estão localizados os países que receberam as primeiras etapas terceirizadas pelo grupo anterior (Tigres Asiáticos), e que já vem alterando seu padrão de atuação, com evolução quanto à atividade desempenhada nas cadeias inclusive em termos de criação de novas marcas. Ressalta-se ainda a Índia, com atuação crescente em serviços de TI e alguns países europeus, com crescimento de serviços na sua estrutura produtiva, mas ainda com pouca representatividade na mesma.

Tabela 2 - Justificativas do padrão de atuação

\begin{tabular}{|c|c|c|}
\hline Grupos & Indicadores que caracterizam o padrão de atuação nas cadeias & $\begin{array}{l}\text { Padrão de atuação } \\
\quad \text { (upgrading) }\end{array}$ \\
\hline G1 & $\begin{array}{c}\Delta \mathrm{IP} \text { médio, } \Delta \text { produtividade e ME médios, } \\
\text { (Coreia: } \Delta I P \text { elevado, } \Delta \text { produtividade e ME elevado) } \\
\uparrow \Delta \mathrm{VAXs} \text { e } \downarrow \Delta \mathrm{VAX}, \uparrow \operatorname{Exp} \mathrm{HT} \text { baixos }\end{array}$ & cadeia e/ou funcional \\
\hline G2 & $\begin{array}{c}\Delta \mathrm{IP} \text { elevado, } \Delta \text { produtividade elevada e ME }=0, \\
\uparrow \Delta \mathrm{VAX}, \uparrow \text { Exp HT elevado (Filipinas)/ } \downarrow \text { Exp HT (Malásia) }\end{array}$ & $\begin{array}{l}\text { Lock-in posterior à } \\
\text { cadeia e/ou funcional }\end{array}$ \\
\hline G3 & $\begin{array}{c}\Delta \mathrm{IP} \text { médio/elevado, } \Delta \text { produtividade e ME elevados, } \\
\uparrow \Delta \mathrm{VAXs}\end{array}$ & cadeia e/ou funcional \\
\hline G4 & $\begin{array}{c}\Delta \text { IP médio/elevado, } \Delta \text { produtividade e ME elevados, } \\
\uparrow \text { Exp HT elevado } \\
\text { (Tailândia: } \downarrow \Delta \operatorname{Exp} H T e \uparrow \Delta V A X)\end{array}$ & 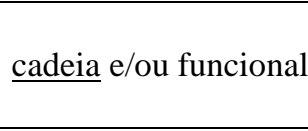 \\
\hline G5 & $\begin{array}{c}\Delta \text { IP médio/alto, } \Delta \text { produtividade elevada e ME baixas (ou ME negativa) } \\
\uparrow \text { ExpHT elevado, } \downarrow \Delta \text { VAX }\end{array}$ & produto e processo \\
\hline G6 & $\begin{array}{c}\Delta \text { IP baixo/médio, } \Delta \text { produtividade e ME baixas, } \\
\text { VAX }>1 \text { e } \uparrow \Delta V A X, \text { recursos naturais/automobilístico (México) }\end{array}$ & $\begin{array}{l}\text { sem evolução e/ou } \\
\text { produto e processo }\end{array}$ \\
\hline
\end{tabular}

Notas: $\Delta$ - variação; IP - índice de participação; ME - mudança estrutural; VAXs - participação de serviços em VA nas exportações; VAX - saldo em VA intra-cadeia; Exp HT - exportações intensivas em alta intensidade tecnológica

O segundo padrão identificado refere-se aos países que reduziram a participação dos serviços nas exportações ao mesmo tempo em que aumentaram a participação de manufaturas intensivas em tecnologia na mesma. Grande parte desses também apresentou aumento do saldo valor adicionado intracadeia. Essas características foram interpretadas como sendo países em que o padrão de atuação na cadeia envolveu além da inserção, uma evolução em termos de upgrading de cadeia. Nesse padrão de atuação, encontram-se os países do grupo 4, em que a inserção nas cadeias ocorreu, em geral, em cadeias mais simples característicos de setores tradicionais como alimento e têxtil, mas que vem alterando essa composição da estrutura produtiva com participação crescente de setores intensivos em tecnologia, como equipamentos eletrônicos e de transporte. Para muitos desses países, embora a participação nas cadeias venha-lhes permitindo avançar em seus processos de industrialização, continuam desempenhando frequentemente atividades de baixo valor adicionado. A continuidade da mudança estrutural rumo a estágios mais elevado requer uma maior endogenização tecnológica dessa atuação que é dificultada pelo tipo de atividade desempenhada até então. No entanto, ressalta-se a China, que apesar de estar trilhando o mesmo caminho em termos de padrão de atuação, encontra-se adiantada comparada aos outros países desse mesmo grupo.

Sobre os países que apresentaram crescimento significativo no índice de participação nas cadeias, mas não acompanhados da mesma intensidade de mudança estrutural, dois aspectos devem ser ressaltados. O primeiro refere-se aos países do grupo 5 que apresentaram características similares ao grupo 4, mas com mudança estrutural baixa ou negativa. Observou-se nesses países, dado suas estruturas produtivas existentes, que a inserção nesta dinâmica produtiva já ocorreu em cadeias mais sofisticadas, como de eletrônicos e automotivas, com a participação nas cadeias não representando um avanço em seus processos industrializantes. No grupo 2, que também apresentam características similares ao grupo 4, mas com mudança estrutural nula, interpreta-se como estando aprisionados em suas estruturas produtivas no período, sem que o upgrading de cadeia e/ou funcional obtidos anteriormente contribuísse para estruturas produtivas mais desenvolvidas. A Malásia, caracterizando-se como um exemplo de armadilha da renda 
média, mas no contexto do paradigma de produção fragmentada internacionalmente, e Filipinas, como um exemplo de decolagem do processo de industrialização impulsionado por plataformas de exportação com efeitos limitados de longo prazo.

E por fim, os países com pouco crescimento da participação nas cadeias em paralelo ao baixo desempenho em termos de mudança estrutural. Esses países caracterizam-se em grande parte por uma atuação via exportação de recursos naturais, e com limitados efeitos em termos de deslocamento dos países para estruturas produtivas mais produtivas.

\section{CONCLUSÃO}

Procurou-se neste trabalho fazer um mapeamento do padrão de atuação dos países nas CGV, associando-se os diferentes resultados obtidos aos caminhos percorridos pelos países em termos de upgrading. Com o mapeamento foi possível identificar entre os países com elevada mudança estrutural em paralelo ao crescimento elevado da participação nas cadeias, dois padrões de comportamento entre os indicadores, definindo-se dessa forma, os caminhos percorridos em termos de upgrading.

$\mathrm{O}$ primeiro refere-se aos países que avançaram em termos de upgrading funcional. Entre esses países, têm-se os desenvolvidos, onde foi iniciado o processo de fragmentação da produção, com as grandes corporações restringindo suas atuações às atividades intensivas em conhecimento. Percorrendo esse mesmo caminho, identificam-se também os Tigres Asiáticos, Índia e alguns países do leste europeu. Nos dois primeiros, a participação dos serviços em suas estruturas produtivas é significativa, evidenciando a maior sofisticação das atividades desempenhadas nas cadeias e com grande efeito de transbordamento sobre a economia. $\mathrm{O}$ segundo caminho refere-se àqueles que avançaram em termos de upgrading de cadeia. Estes países embora desempenhem atividades pouco intensivas em conhecimento, o efeito positivo da atuação em cadeias mais sofisticadas sobre o estágio produtivo foi possibilitado por se encontrarem em estágios iniciais e, com isso, a participação nas cadeias contribuindo para a decolagem e aprofundamento de seus processos industrializantes. A continuidade da mudança estrutural em direção a estágios mais elevados requer uma sofisticação inclusive das atividades desempenhadas e com maior potencial de endogenização tecnológica.

\section{BIBLIOGRAFIA}

BALDWIN, R. Global Supply Chains: Why they Emerged, Why they Matters, and Where They Are Going. Fung Global Institute, Working Paper 2012-01.

BANGA, R. Measuring value in global value chains. Unit of Economic Cooperation and Integration amongst Developing Countries (ECIDC) - UNCTAD. Background paper n. RVC-8, 2013.

EICHENGREEN, B. Escaping the Middle Income Trap, manuscrito preparado para Economic Policy Symposium 2011, realizado por Federal Reserve Bank of Kansas City.

HUMMELS, D., ISHII, J. e YI, K. M. "The Nature and Growth of Vertical Specialization in World Trade”, Journal of International Economics, 54(1), pp. 75-96, 2001.

HUMPHREY, J., SCHMITZ, H. How does insertion in global value chains affect upgrading in industrial clusters?, Regional Studies, 36:1017-1027, 2002.

JOHNSON, R. e WICHERN, D. Applied Multivariate Statistical Analysis. Editora Pearson, New Jersey, 2007.

KUCERA, D. e RONCOLATO, L. Structure Matters: Sectorial Drivers of Growth and the Labour Productivity Employment Relationship, ILO Research paper no. 3, 2012.

LALL, S. "The technological structure and performance of developing country manufactured exports, 1985-98", Oxford Development Studies, 28(3), pp. 337- 369, 2000.

MACMILLAN, M. e RODRIK, D. Globalization, Structural Change and Productivity in Making

Globalization Socially Sustentable. Genebra: WTO, 2011.

MEMEDOVIC, O. e IAPADRE, L. "Structural Change in the World Economy: Main Features and Change", UNIDO, Research and Statistics Branch, Working Paper no. 24/2009.

MILBERG, W. e WINKLER, D. Outsourcing Economics: global value chains in capitalist development.

New York. Cambridge University Press, 2013. 
OECD-WTO, “Trade in Value-Added: Concepts, Methodologies and Challenges", Joint OECD_WTO Note, March 15, 2012.

OECD. Compendium of Productivity Indicators 2013. Paris: OECD, 2013.

PIETROBELLI, C. e RABELLOTI, R."Clusters and value chains in Latin America: In search of an integrated approach".In C.Pietrobelli, \&R. Rabellotti, Upgrading to 39 Compete: Global Value Chains, Clusters and SMEs in Latin America (pp.1-40).Washington,DC: American Development Bank, 2006.

SARTI, F.e HIRATUKA, C.(Coords.). Perspectivas do investimento na indústria. Rio de Janeiro: Synergia:UFRJ,Instituto de Economia;Campinas:UNICAMP, Instituto de Economia,2010.

STURGEON, T. \& GEREFFI, G. Measuring Success in the Global Economy: International Trade, Industrial Upgrading, and Business Function Outsourcing in Global Value Chains. Transnational Corporations, Vol. 18, no. 2, pp. 1-36, 2009.

UNCTAD. World Investment Report 2013: Global Value Chains: Investiment and Trade for development (WIR 13). New York and Geneva: United Nations, 2013.

UNIDO (United Nations Industrial Development Organization). Industrial Development Report 2013: Sustaining Employment Growth: The Role of Manufacturing and Structural Change. Viena, 2013.

ANEXO

Tabela 1: Indicadores de inserção e upgrading nas cadeias globais de valor

\begin{tabular}{|c|c|c|c|c|c|c|c|c|c|c|c|c|}
\hline & 1 & 2 & 3 & 4 & 5 & 6 & 7 & 8 & 9 & 10 & 11 & 12 \\
\hline & $\begin{array}{c}\Delta \operatorname{Exp} \\
H T\end{array}$ & $\Delta \mathrm{IP}$ & $\begin{array}{c}\Delta\left(\mathrm{VAX}^{*} /\right. \\
\left.\mathrm{VA}^{*} \mathrm{X}\right)\end{array}$ & $\begin{array}{c}\Delta[(\mathrm{VAXs}+ \\
\left.\left.\mathrm{VA}{ }^{*} \mathrm{Xs}\right) / \mathrm{X}\right]\end{array}$ & $\begin{array}{c}\Delta(\text { VAXs } / \\
\text { VAX) }\end{array}$ & $\begin{array}{c}\Delta\left(\text { VAX }_{s}\right. \\
a, b, c / \\
\text { VAX })\end{array}$ & $\begin{array}{l}\text { IDE } \\
\text { líquido }\end{array}$ & $\begin{array}{l}\triangle I D E \\
\text { liquido }\end{array}$ & $\begin{array}{c}\Delta \text { Intens. } \\
\text { IDE }\end{array}$ & $\Delta$ Produt. & $\begin{array}{l}\text { Mud. } \\
\text { Estrutural } \\
\text { (ME) }\end{array}$ & $\begin{array}{c}\text { ME/ } \\
\text { Produt. }\end{array}$ \\
\hline & $\Delta 95-08$ & $\Delta 95 / 08$ & $\Delta 95 / 08$ & $\Delta 95 / 08$ & $\Delta 95 / 08$ & $\Delta 95-08$ & $06 / 07 / 08$ & $\Delta 95-08$ & $\Delta 95-08$ & $\Delta 99 / 08$ & $\Delta 99 / 08$ & $\Delta 99 / 08$ \\
\hline África do Sul & 0,01 & $-0,06$ & $-1,93$ & 0,01 & 0,02 & 0,01 & $-0,98$ & $-0,98$ & $-0,09$ & 2,50 & 0,60 & 0,24 \\
\hline Alemanha & 0,00 & 0,11 & $-0,34$ & 0,06 & 0,07 & 0,03 & 2,23 & 0,81 & 1,48 & 1,00 & 0,20 & 0,20 \\
\hline Argentina & 0,01 & 0,11 & $-0,27$ & $-0,05$ & $-0,05$ & 0,00 & $-1,96$ & $-0,15$ & $-0,02$ & $-0,80$ & $-0,30$ & 0,38 \\
\hline Austrália & $-0,04$ & 0,15 & 0,68 & $-0,02$ & $-0,02$ & $-0,01$ & $-1,78$ & $-0,89$ & 1,68 & 0,80 & 0,30 & 0,38 \\
\hline Áustria & 0,03 & 0,11 & $-0,08$ & 0,02 & 0,05 & 0,03 & 3,11 & 3,66 & 4,67 & 1,50 & $-0,10$ & $-0,07$ \\
\hline Bélgica & $-0,01$ & 0,05 & 0,09 & 0,07 & 0,11 & 0,11 & 0,13 & 1,39 & 20,57 & 0,70 & 0,00 & 0,00 \\
\hline Brasil & 0,03 & 0,09 & 0,32 & 0,01 & 0,01 & 0,01 & $-0,88$ & 0,39 & 1,18 & 1,00 & 0,40 & 0,40 \\
\hline Bulgária & 0,02 & 0,04 & 0,00 & 0,00 & 0,04 & 0,03 & $-23,09$ & $-20,69$ & 11,37 & 3,50 & $-0,10$ & $-0,03$ \\
\hline Camboja & 0,00 & $-0,03$ & $-0,55$ & 0,10 & 0,14 & 0,08 & $-8,08$ & $-2,14$ & 1,18 & - & - & - \\
\hline Canadá & $-0,02$ & 0,05 & 0,38 & 0,03 & 0,03 & 0,00 & $-1,17$ & $-2,07$ & 2,89 & 0,90 & 0,00 & 0,00 \\
\hline Chile & 0,01 & 0,19 & 0,25 & $-0,02$ & $-0,03$ & $-0,02$ & $-3,79$ & 0,26 & 1,58 & 1,50 & 0,00 & 0,00 \\
\hline China & 0,20 & 0,22 & $-0,74$ & 0,00 & $-0,01$ & $-0,06$ & $-1,54$ & 2,95 & $-0,81$ & 7,40 & 4,10 & 0,55 \\
\hline Cingapura & $-0,10$ & 0,14 & 0,09 & 0,04 & 0,03 & 0,05 & $-7,16$ & $-3,43$ & 3,97 & 2,60 & 0,30 & 0,12 \\
\hline Coreia & $-0,01$ & 0,30 & $-0,02$ & $-0,01$ & 0,03 & 0,03 & 0,85 & 0,57 & 0,76 & 3,90 & 0,30 & 0,08 \\
\hline Eslováquia & 0,17 & 0,11 & $-0,19$ & $-0,01$ & $-0,01$ & $-0,07$ & $-6,10$ & $-0,93$ & 1,17 & 4,60 & 0,20 & 0,04 \\
\hline Espanha & 0,00 & 0,05 & $-0,13$ & 0,04 & 0,05 & 0,11 & 3,62 & 3,61 & 4,27 & $-0,30$ & $-0,10$ & 0,33 \\
\hline Estados Unidos & $-0,05$ & 0,11 & $-0,90$ & 0,06 & 0,08 & 0,05 & 0,38 & 0,27 & 0,88 & 1,70 & $-0,20$ & $-0,12$ \\
\hline Filipinas & 0,33 & 0,25 & 0,21 & $-0,04$ & $-0,04$ & $-0,12$ & 0,22 & 1,67 & 0,88 & 3,30 & 0,00 & 0,00 \\
\hline França & 0,00 & 0,09 & $-0,43$ & 0,03 & 0,06 & 0,03 & 2,52 & 2,21 & 2,65 & 0,70 & $-0,10$ & $-0,14$ \\
\hline Holanda & 0,02 & 0,07 & 0,11 & 0,00 & 0,05 & 0,02 & 2,54 & $-0,41$ & 2,55 & 1,20 & $-0,20$ & $-0,17$ \\
\hline Hong Kong & 0,24 & 0,06 & 0,72 & 0,20 & 0,16 & 0,14 & $-0,14$ & $-10,28$ & 16,82 & 3,50 & 0,60 & 0,17 \\
\hline Hungria & 0,20 & 0,21 & $-0,18$ & $-0,02$ & $-0,02$ & $-0,07$ & $-1,84$ & 6,91 & $-1,31$ & 3,30 & $-0,30$ & $-0,09$ \\
\hline Índia & 0,02 & 0,22 & $-0,53$ & 0,15 & 0,18 & 0,17 & $-1,11$ & $-0,45$ & 1,71 & 5,30 & 0,20 & 0,04 \\
\hline Indonésia & 0,03 & 0,16 & 0,55 & $-0,04$ & $-0,05$ & 0,00 & $-0,60$ & 1,26 & 0,06 & 3,20 & 1,50 & 0,47 \\
\hline Irlanda & 0,00 & 0,12 & 0,06 & 0,25 & 0,27 & 0,26 & 7,13 & 8,81 & 1,96 & 1,9 & $-0,8$ & $-0,42$ \\
\hline Israel & 0,02 & 0,11 & 0,05 & $-0,05$ & $-0,08$ & 0,01 & $-0,61$ & 0,49 & 5,65 & 1,20 & 0,30 & 0,25 \\
\hline Itália & $-0,02$ & 0,07 & 0,22 & 0,03 & 0,06 & 0,03 & 1,97 & 1,66 & 1,75 & $-0,10$ & 0,00 & 0,00 \\
\hline Japão & $-0,13$ & 0,21 & $-1,69$ & 0,01 & 0,03 & 0,02 & 1,54 & 1,06 & 0,79 & 1,50 & 0,10 & 0,07 \\
\hline Malásia & $-0,10$ & 0,12 & 0,40 & $-0,01$ & $-0,02$ & $-0,02$ & 1,59 & 4,94 & 0,03 & 3,60 & 0,00 & 0,00 \\
\hline
\end{tabular}




\begin{tabular}{|lllllllllllll|}
\hline México & 0,05 & 0,08 & 0,07 & $-0,02$ & $-0,04$ & $-0,02$ & $-2,11$ & 0,42 & 0,23 & 1,10 & 0,30 & 0,27 \\
Polônia & 0,07 & 0,19 & $-0,43$ & 0,01 & 0,03 & 0,02 & $-3,13$ & $-0,28$ & 1,68 & 4,60 & 0,10 & 0,02 \\
Portugal & 0,03 & 0,12 & 0,05 & 0,04 & 0,07 & 0,04 & $-0,53$ & $-0,29$ & 1,49 & 0,80 & 0,40 & 0,50 \\
Reino Unido & $-0,12$ & 0,03 & 0,34 & 0,14 & 0,16 & 0,20 & 1,64 & 0,04 & 3,53 & 1,60 & $-0,10$ & $-0,06$ \\
República Checa & 0,13 & 0,12 & $-0,02$ & $-0,02$ & $-0,03$ & $-0,04$ & $-2,84$ & $-0,01$ & 1,16 & 3,90 & $-0,20$ & $-0,05$ \\
Romênia & 0,06 & 0,11 & 0,07 & 0,02 & 0,03 & 0,03 & $-7,08$ & $-5,33$ & 2,89 & 6,60 & 0,70 & 0,11 \\
Rússia & $-0,01$ & 0,14 & 3,76 & $-0,04$ & $-0,03$ & $-0,01$ & $-0,92$ & $-0,52$ & 3,15 & 6,50 & $-0,10$ & $-0,02$ \\
Tailândia & $-0,03$ & 0,15 & 0,09 & $-0,05$ & $-0,06$ & $-0,03$ & $-2,86$ & $-1,63$ & 1,34 & 2,90 & 0,80 & 0,28 \\
Taiwan & 0,00 & 0,27 & 0,22 & 0,02 & 0,10 & $-0,02$ & 0,69 & $-0,05$ & 1,09 & 3,0 & 0,5 & 0,17 \\
Turquia & 0,02 & 0,18 & $-0,57$ & $-0,05$ & $-0,03$ & $-0,10$ & $-3,02$ & $-2,75$ & 1,59 & 3,60 & 1,10 & 0,31 \\
Vietnã & 0,04 & 0,19 & $-0,10$ & $-0,10$ & $-0,12$ & $-0,03$ & $-7,21$ & 1,65 & $-0,60$ & 4,30 & 2,60 & 0,60 \\
\hline
\end{tabular}

Notas: O saldo do IDE refere-se à média dos anos 2006, 2007 e 2008. Utilizou-se (-) para informação não disponível.

Tabela 2- Grupos formados com os indicadores categorizados.

\begin{tabular}{|c|c|c|c|c|c|c|c|c|c|c|c|c|}
\hline & 1 & 2 & 3 & 4 & 5 & 6 & 7 & 8 & 9 & 10 & 11 & 12 \\
\hline & $\begin{array}{c}\Delta \operatorname{Exp} \\
H T\end{array}$ & $\Delta I P$ & $\begin{array}{c}\Delta\left(\mathrm{VAX}^{*} /\right. \\
\left.\mathrm{VA}{ }^{*} \mathrm{X}\right)\end{array}$ & $\begin{array}{c}\Delta[(\mathrm{VAXs}+ \\
\left.\left.\mathrm{VA}^{*} \mathrm{Xs}\right) / \mathrm{X}\right]\end{array}$ & $\begin{array}{c}\Delta \text { (VAXs/ } \\
\text { VAX) }\end{array}$ & $\begin{array}{c}\Delta\left(\text { VAX }_{S}\right. \\
\mathrm{a}, \mathrm{b}, \mathrm{c} / \\
\text { VAX })\end{array}$ & $\begin{array}{l}\text { IDE } \\
\text { líquido }\end{array}$ & $\begin{array}{l}\triangle I D E \\
\text { liquido }\end{array}$ & $\begin{array}{l}\Delta \text { Intens. } \\
\text { IDE }\end{array}$ & $\Delta$ Produt & $\begin{array}{l}\text { Mud. } \\
\text { Estrut. } \\
\text { (ME) }\end{array}$ & $\begin{array}{l}\text { ME/ } \\
\text { Produt. }\end{array}$ \\
\hline & $\Delta 95-08$ & $\Delta 95 / 08$ & $\Delta 95 / 08$ & $\Delta 95 / 08$ & $\Delta 95 / 08$ & $\Delta 95-08$ & $06 / 07 / 2008$ & $\Delta 95-08$ & $\Delta 95-08$ & $\Delta 99 / 08$ & $\Delta 99 / 08$ & $\Delta 99 / 08$ \\
\hline Alemanha & 2,00 & 2,00 & 0,50 & 4,00 & 4,00 & 3,00 & 4,00 & 3,00 & 3,00 & 0,50 & 3,00 & 3,00 \\
\hline EUA & 0,50 & 2,00 & 0,50 & 4,00 & 4,00 & 4,00 & 3,00 & 3,00 & 2,00 & 2,00 & 0,50 & 0,50 \\
\hline Japão & 0,50 & 4,00 & 0,50 & 3,00 & 3,00 & 3,00 & 3,00 & 3,00 & 2,00 & 2,00 & 2,00 & 3,00 \\
\hline Coreia & 0,50 & 4,00 & 1,50 & 1,50 & 3,00 & 3,00 & 3,00 & 3,00 & 2,00 & 4,00 & 3,00 & 3,00 \\
\hline Irlanda & 2,00 & 3,00 & 3,00 & 4,00 & 4,00 & 4,00 & 4,00 & 4,00 & 3,00 & 2,00 & 0,50 & 0,50 \\
\hline Áustria & 3,00 & 2,00 & 1,50 & 3,00 & 3,00 & 3,00 & 4,00 & 4,00 & 4,00 & 2,00 & 0,50 & 0,50 \\
\hline França & 2,00 & 2,00 & 0,50 & 3,00 & 4,00 & 4,00 & 4,00 & 4,00 & 4,00 & 0,50 & 0,50 & 0,50 \\
\hline Espanha & 2,00 & 1,00 & 1,50 & 4,00 & 3,00 & 4,00 & 4,00 & 4,00 & 4,00 & 0,50 & 0,50 & 4,00 \\
\hline Bélgica & 0,50 & 1,00 & 3,00 & 4,00 & 4,00 & 4,00 & 3,00 & 4,00 & 4,00 & 0,50 & 2,00 & 2,00 \\
\hline Holanda & 3,00 & 1,00 & 3,00 & 1,50 & 3,00 & 3,00 & 4,00 & 1,50 & 3,00 & 2,00 & 0,50 & 0,50 \\
\hline Italia & 0,50 & 1,00 & 4,00 & 3,00 & 4,00 & 3,00 & 4,00 & 4,00 & 3,00 & 0,50 & 2,00 & 2,00 \\
\hline R. Unido & 0,50 & 1,00 & 4,00 & 4,00 & 4,00 & 4,00 & 4,00 & 3,00 & 4,00 & 2,00 & 0,50 & 0,50 \\
\hline Filipinas & 4,00 & 4,00 & 3,00 & 0,50 & 0,50 & 0,50 & 3,00 & 4,00 & 2,00 & 3,00 & 2,00 & 2,00 \\
\hline Malásia & 0,50 & 3,00 & 4,00 & 1,50 & 1,50 & 1,50 & 3,00 & 4,00 & 2,00 & 3,00 & 2,00 & 2,00 \\
\hline Cingapura & 0,50 & 3,00 & 3,00 & 4,00 & 3,00 & 4,00 & 0,50 & 0,50 & 4,00 & 3,00 & 3,00 & 3,00 \\
\hline Taiwan & 3,00 & 4,00 & 4,00 & 3,00 & 4,00 & 1,50 & 3,00 & 1,50 & 2,00 & 3,00 & 4,00 & 3,00 \\
\hline Índia & 3,00 & 4,00 & 0,50 & 4,00 & 4,00 & 4,00 & 1,50 & 1,50 & 3,00 & 4,00 & 3,00 & 2,00 \\
\hline Romênia & 4,00 & 2,00 & 3,00 & 3,00 & 3,00 & 3,00 & 0,50 & 0,50 & 4,00 & 4,00 & 4,00 & 3,00 \\
\hline Polônia & 4,00 & 4,00 & 0,50 & 3,00 & 3,00 & 3,00 & 0,50 & 1,50 & 3,00 & 4,00 & 2,00 & 2,00 \\
\hline Hong Kong & 4,00 & 1,00 & 4,00 & 4,00 & 4,00 & 4,00 & 1,50 & 0,50 & 4,00 & 3,00 & 4,00 & 3,00 \\
\hline Bulgária & 3,00 & 1,00 & 1,50 & 1,50 & 3,00 & 3,00 & 0,50 & 0,50 & 4,00 & 3,00 & 0,50 & 0,50 \\
\hline Canadá & 0,50 & 1,00 & 4,00 & 3,00 & 3,00 & 1,50 & 1,50 & 0,50 & 4,00 & 0,50 & 2,00 & 2,00 \\
\hline Camboja & 2,00 & 1,00 & 0,50 & 4,00 & 4,00 & 4,00 & 0,50 & 0,50 & 2,00 & - & - & - \\
\hline Turquia & 3,00 & 4,00 & 0,50 & 0,50 & 1,50 & 0,50 & 0,50 & 0,50 & 3,00 & 3,00 & 4,00 & 4,00 \\
\hline China & 4,00 & 4,00 & 0,50 & 3,00 & 1,50 & 0,50 & 1,50 & 4,00 & 0,50 & 4,00 & 4,00 & 4,00 \\
\hline Vietnã & 3,00 & 4,00 & 1,50 & 0,50 & 0,50 & 0,50 & 0,50 & 4,00 & 0,50 & 4,00 & 4,00 & 4,00 \\
\hline Tailândia & 0,50 & 3,00 & 3,00 & 0,50 & 0,50 & 0,50 & 0,50 & 0,50 & 3,00 & 3,00 & 4,00 & 3,00 \\
\hline Indonésia & 3,00 & 3,00 & 4,00 & 0,50 & 0,50 & 1,50 & 1,50 & 4,00 & 2,00 & 3,00 & 4,00 & 4,00 \\
\hline Eslováquia & 4,00 & 2,00 & 1,50 & 1,50 & 1,50 & 0,50 & 0,50 & 1,50 & 2,00 & 4,00 & 3,00 & 2,00 \\
\hline Rep. Checa & 4,00 & 3,00 & 1,50 & 1,50 & 1,50 & 0,50 & 0,50 & 1,50 & 2,00 & 4,00 & 0,50 & 0,50 \\
\hline Hungria & 4,00 & 4,00 & 1,50 & 1,50 & 1,50 & 0,50 & 1,50 & 4,00 & 0,50 & 3,00 & 0,50 & 0,50 \\
\hline Rússia & 0,50 & 3,00 & 4,00 & 0,50 & 1,50 & 1,50 & 1,50 & 1,50 & 4,00 & 4,00 & 0,50 & 0,50 \\
\hline Austrália & 0,50 & 3,00 & 4,00 & 1,50 & 1,50 & 1,50 & 1,50 & 1,50 & 3,00 & 0,50 & 3,00 & 4,00 \\
\hline Chile & 2,00 & 4,00 & 4,00 & 1,50 & 1,50 & 1,50 & 0,50 & 3,00 & 3,00 & 2,00 & 2,00 & 2,00 \\
\hline México & 4,00 & 2,00 & 3,00 & 1,50 & 0,50 & 1,50 & 0,50 & 3,00 & 2,00 & 2,00 & 3,00 & 3,00 \\
\hline Brasil & 3,00 & 2,00 & 4,00 & 3,00 & 3,00 & 3,00 & 1,50 & 3,00 & 2,00 & 0,50 & 3,00 & 4,00 \\
\hline Portugal & 3,00 & 3,00 & 3,00 & 4,00 & 4,00 & 4,00 & 1,50 & 1,50 & 3,00 & 0,50 & 3,00 & 4,00 \\
\hline Israel & 3,00 & 2,00 & 3,00 & 0,50 & 0,50 & 3,00 & 1,50 & 3,00 & 4,00 & 2,00 & 3,00 & 3,00 \\
\hline
\end{tabular}




\begin{tabular}{|c|c|c|c|c|c|c|c|c|c|c|c|c|}
\hline Argentina & 2,00 & 2,00 & 1,50 & 0,50 & 0,50 & 1,50 & 0,50 & 1,50 & 0,50 & 0,50 & 0,50 & 4,00 \\
\hline Áfr. do Sul & 2,00 & 1,00 & 0,50 & 3,00 & 3,00 & 3,00 & 1,50 & 1,50 & 0,50 & 3,00 & 4,00 & 3,00 \\
\hline
\end{tabular}

Nota: Os valores 0,50 e 1,50 referem-se a intervalos com variação negativa, enquanto 2,00, 3,00 e 4,00 referem-se à variação positiva.

Tabela 3 e 4 - Participação setorial das exportações em 2008 e variação entre 1995/2008 desagregada em 18 setores TIVA-OCDE - versão maio de 2013.

\begin{tabular}{|c|c|c|c|c|c|c|c|c|c|c|c|c|c|c|c|c|}
\hline \multirow[b]{3}{*}{ EXPORTAÇÕES } & \multicolumn{4}{|c|}{ Grupo 2} & \multicolumn{10}{|c|}{ Grupo 4} & \multirow{2}{*}{\multicolumn{2}{|c|}{$\begin{array}{l}\text { Grupo } 5 \\
\text { Hungria }\end{array}$}} \\
\hline & \multicolumn{2}{|c|}{ Malásia } & \multicolumn{2}{|c|}{ Filipinas } & \multicolumn{2}{|c|}{ Turquia } & \multicolumn{2}{|c|}{ Tailândia } & \multicolumn{2}{|c|}{ China } & \multicolumn{2}{|c|}{ Vietnã } & \multicolumn{2}{|c|}{ Indonésia } & & \\
\hline & 2008 & $\Delta 95 / 08$ & 2008 & $\Delta 95 / 08$ & 2008 & $\Delta 95 / 08$ & 2008 & $\Delta 95 / 08$ & 2008 & $\Delta 95 / 08$ & 2008 & $\Delta 95 / 08$ & 2008 & $\Delta 95 / 08$ & 2008 & $\Delta 95 / 08$ \\
\hline TOTAL & 1 & & 1 & & 1 & & 1 & & 1 & & 1 & & 1 & & 1 & \\
\hline Agricultura, silvicultura e pesca & 0,08 & $-0,04$ & 0,02 & $-0,01$ & 0,03 & $-0,03$ & 0,02 & 0,00 & 0,01 & $-0,02$ & 0,22 & 0,02 & 0,02 & 0,01 & 0,03 & $-0,05$ \\
\hline Mineração e pedreiras & 0,17 & 0,09 & 0,01 & $-0,04$ & 0,01 & 0,00 & 0,01 & 0,00 & 0,01 & $-0,01$ & 0,18 & 0,00 & 0,17 & $-0,03$ & 0,00 & 0,00 \\
\hline Produtos alimentares, bebidas.. & 0,03 & 0,00 & 0,01 & $-0,03$ & 0,04 & $-0,01$ & 0,13 & 0,02 & 0,02 & $-0,03$ & 0,15 & 0,05 & 0,15 & 0,04 & 0,03 & $-0,08$ \\
\hline Têxteis, vestuário e calçados & 0,02 & 0,00 & 0,06 & $-0,12$ & 0,15 & $-0,09$ & 0,10 & 0,01 & 0,15 & $-0,10$ & 0,21 & 0,01 & 0,09 & $-0,10$ & 0,02 & $-0,04$ \\
\hline Madeira, papel, produtos de, ... & 0,04 & 0,00 & 0,01 & $-0,02$ & 0,01 & 0,01 & 0,02 & 0,00 & 0,02 & 0,01 & 0,03 & 0,01 & 0,05 & $-0,08$ & 0,02 & $-0,01$ \\
\hline Prod. quím. e minerais não-met. & 0,17 & $-0,01$ & 0,02 & $-0,02$ & 0,13 & 0,06 & 0,12 & 0,02 & 0,11 & 0,01 & 0,02 & 0,01 & 0,21 & 0,07 & 0,14 & $-0,01$ \\
\hline Metais de base e prod. metálicos & 0,02 & 0,00 & 0,01 & $-0,05$ & 0,18 & 0,10 & 0,04 & 0,01 & 0,08 & 0,01 & 0,01 & 0,01 & 0,05 & 0,02 & 0,07 & $-0,03$ \\
\hline Maquinas e equipamentos, nec. & 0,10 & 0,00 & 0,01 & 0,00 & 0,05 & 0,04 & 0,02 & 0,00 & 0,08 & 0,03 & 0,01 & 0,00 & 0,04 & 0,02 & 0,05 & 0,01 \\
\hline Equipamentos elétricos e óptico & 0,22 & $-0,02$ & 0,64 & 0,48 & 0,04 & 0,02 & 0,29 & $-0,03$ & 0,31 & 0,16 & 0,03 & 0,01 & 0,07 & 0,03 & 0,28 & 0,21 \\
\hline Equipamento de transporte & 0,01 & 0,00 & 0,03 & 0,03 & 0,14 & 0,11 & 0,03 & 0,01 & 0,04 & 0,02 & 0,01 & 0,01 & 0,03 & 0,01 & 0,18 & 0,12 \\
\hline Indústrias de transf, nec.; recicl. & 0,00 & 0,00 & 0,00 & $-0,03$ & 0,02 & 0,01 & 0,05 & 0,01 & 0,06 & $-0,03$ & 0,02 & 0,01 & 0,02 & 0,01 & 0,01 & 0,00 \\
\hline Eletricidade, gás e água & 0,00 & 0,00 & 0,00 & 0,00 & 0,00 & 0,00 & 0,00 & 0,00 & 0,00 & 0,00 & 0,00 & 0,00 & 0,00 & 0,00 & 0,01 & $-0,01$ \\
\hline Construção & 0,00 & 0,00 & 0,00 & 0,00 & 0,02 & 0,02 & 0,00 & 0,00 & 0,00 & 0,00 & 0,00 & 0,00 & 0,00 & 0,00 & 0,00 & $-0,01$ \\
\hline Comércio var./atacad., hotéis, .. & 0,05 & 0,01 & 0,11 & $-0,05$ & 0,05 & $-0,08$ & 0,07 & $-0,01$ & 0,05 & 0,03 & 0,07 & $-0,10$ & 0,03 & $-0,03$ & 0,07 & $-0,01$ \\
\hline Transp., correios e telec. (a) & 0,06 & $-0,01$ & 0,04 & $-0,06$ & 0,08 & $-0,12$ & 0,08 & $-0,02$ & 0,02 & $-0,04$ & 0,02 & $-0,02$ & 0,04 & 0,02 & 0,04 & $-0,05$ \\
\hline Intermediação financeira (b) & 0,01 & 0,00 & 0,01 & $-0,03$ & 0,03 & 0,01 & 0,00 & 0,00 & 0,00 & 0,00 & 0,01 & $-0,01$ & 0,00 & $-0,01$ & 0,00 & $-0,02$ \\
\hline Business services (c) & 0,01 & $-0,01$ & 0,02 & $-0,04$ & 0,01 & $-0,03$ & 0,01 & $-0,02$ & 0,01 & $-0,04$ & 0,00 & 0,00 & 0,01 & 0,01 & 0,04 & $-0,02$ \\
\hline Outros serviços & 0,00 & 0,00 & 0,00 & 0,00 & 0,02 & 0,00 & 0,00 & $-0,01$ & 0,00 & 0,00 & 0,00 & $-0,01$ & 0,02 & 0,01 & 0,01 & 0,00 \\
\hline$\Sigma$ Serviços total & 0,14 & & 0,17 & & 0,22 & & 0,17 & & 0,09 & & 0,11 & & 0,10 & & 0,17 & \\
\hline$\sum$ Serviços (a), (b) e (c) & 0,08 & & 0,07 & & 0,14 & & 0,09 & & 0,04 & & 0,03 & & 0,07 & & 0,09 & \\
\hline
\end{tabular}

\begin{tabular}{|c|c|c|c|c|c|c|c|c|c|c|c|c|c|c|c|c|}
\hline \multirow[b]{3}{*}{ EXPORTAÇÕES } & \multicolumn{4}{|c|}{ Grupo 5} & \multicolumn{12}{|c|}{ Grupo 6} \\
\hline & \multicolumn{2}{|c|}{ Rep. Checa } & \multicolumn{2}{|c|}{ Eslováquia } & \multicolumn{2}{|c|}{ Portugal } & \multicolumn{2}{|c|}{ México } & \multicolumn{2}{|c|}{ Brasil } & \multicolumn{2}{|c|}{ Chile } & \multicolumn{2}{|c|}{ Austrália } & \multicolumn{2}{|c|}{ Rússia } \\
\hline & 2008 & $\Delta 95 / 08$ & 2008 & $\Delta 95 / 08$ & 2008 & $\Delta 95 / 08$ & 2008 & $\Delta 95 / 08$ & 2008 & $\Delta 95 / 08$ & 2008 & $\Delta 95 / 08$ & 2008 & $\Delta 95 / 08$ & 2008 & $\Delta 95 / 08$ \\
\hline TOTAL & 1 & & 1 & & 1 & & 1 & & 1 & & 1 & & 1 & & 1 & \\
\hline Agricultura, silvicultura e pesca & 0,01 & $-0,02$ & 0,02 & $-0,02$ & 0,02 & 0,01 & 0,02 & $-0,01$ & 0,09 & 0,06 & 0,08 & 0,00 & 0,03 & $-0,03$ & 0,03 & $-0,02$ \\
\hline Mineração e pedreiras & 0,01 & $-0,02$ & 0,00 & $-0,01$ & 0,01 & 0,00 & 0,15 & 0,08 & 0,15 & 0,07 & 0,46 & 0,04 & 0,48 & 0,25 & 0,35 & 0,10 \\
\hline Produtos alimentares, bebidas.. & 0,03 & $-0,01$ & 0,04 & 0,00 & 0,05 & 0,01 & 0,03 & 0,00 & 0,14 & $-0,06$ & 0,10 & $-0,03$ & 0,06 & $-0,08$ & 0,01 & $-0,01$ \\
\hline Têxteis, vestuário e calçados & 0,03 & $-0,05$ & 0,03 & $-0,02$ & 0,09 & $-0,14$ & 0,03 & $-0,03$ & 0,03 & $-0,04$ & 0,01 & $-0,01$ & 0,01 & $-0,02$ & 0,00 & $-0,01$ \\
\hline Madeira, papel, produtos de, ... & 0,03 & $-0,02$ & 0,04 & $-0,02$ & 0,06 & $-0,02$ & 0,01 & $-0,01$ & 0,04 & $-0,03$ & 0,10 & 0,01 & 0,01 & $-0,01$ & 0,03 & $-0,02$ \\
\hline Prod. quím. e minerais não-met. & 0,12 & $-0,03$ & 0,14 & $-0,08$ & 0,14 & 0,04 & 0,10 & $-0,01$ & 0,12 & 0,00 & 0,06 & 0,03 & 0,04 & $-0,01$ & 0,22 & 0,06 \\
\hline Metais de base e prod metálicos & 0,10 & $-0,04$ & 0,14 & $-0,04$ & 0,07 & 0,04 & 0,08 & 0,01 & 0,11 & $-0,05$ & 0,02 & 0,00 & 0,14 & $-0,03$ & 0,16 & $-0,05$ \\
\hline Maquinas e equipamentos, nec. & 0,11 & 0,04 & 0,07 & 0,02 & 0,03 & 0,01 & 0,03 & 0,01 & 0,04 & 0,00 & 0,01 & 0,00 & 0,02 & 0,00 & 0,05 & $-0,02$ \\
\hline Equipamentos elétricos e óptico & 0,22 & 0,16 & 0,16 & 0,13 & 0,08 & $-0,01$ & 0,25 & 0,01 & 0,03 & 0,00 & 0,00 & 0,00 & 0,01 & $-0,01$ & 0,01 & $-0,01$ \\
\hline Equipamento de transporte & 0,16 & 0,08 & 0,22 & 0,15 & 0,10 & 0,01 & 0,20 & 0,01 & 0,11 & 0,03 & 0,01 & 0,00 & 0,02 & $-0,01$ & 0,02 & $-0,02$ \\
\hline Indústrias de transf, nec.; recicl. & 0,03 & 0,00 & 0,02 & 0,00 & 0,01 & 0,00 & 0,03 & $-0,02$ & 0,01 & 0,00 & 0,00 & 0,00 & 0,00 & 0,00 & 0,00 & 0,00 \\
\hline Eletricidade, gás e água & 0,01 & 0,00 & 0,00 & 0,00 & 0,00 & 0,00 & 0,00 & 0,00 & 0,00 & 0,00 & 0,00 & 0,00 & 0,00 & 0,00 & 0,01 & 0,00 \\
\hline Construção & 0,00 & 0,00 & 0,00 & $-0,01$ & 0,00 & 0,00 & 0,00 & 0,00 & 0,00 & 0,00 & 0,00 & 0,00 & 0,00 & 0,00 & 0,00 & 0,00 \\
\hline Comércio var./atacad., hotéis, ... & 0,04 & $-0,01$ & 0,03 & $-0,04$ & 0,06 & 0,03 & 0,04 & $-0,04$ & 0,04 & 0,01 & 0,05 & $-0,01$ & 0,03 & $-0,04$ & 0,05 & $-0,01$ \\
\hline Transp., correios e telec. (a) & 0,05 & $-0,04$ & 0,03 & $-0,06$ & 0,18 & 0,01 & 0,02 & $-0,01$ & 0,04 & $-0,02$ & 0,07 & $-0,03$ & 0,09 & $-0,02$ & 0,05 & $-0,01$ \\
\hline Intermediação financeira (b) & 0,00 & 0,00 & 0,00 & $-0,01$ & 0,01 & $-0,01$ & 0,00 & 0,00 & 0,00 & 0,00 & 0,01 & 0,00 & 0,01 & 0,00 & 0,00 & 0,00 \\
\hline Business services (c) & 0,04 & $-0,02$ & 0,02 & $-0,01$ & 0,06 & 0,02 & 0,00 & 0,00 & 0,03 & 0,02 & 0,01 & 0,01 & 0,03 & 0,01 & 0,00 & 0,00 \\
\hline Outros serviços & 0,02 & $-0,03$ & 0,02 & 0,02 & 0,01 & 0,00 & 0,00 & 0,00 & 0,01 & 0,01 & 0,00 & 0,00 & 0,02 & 0,01 & 0,00 & 0,00 \\
\hline$\sum$ Servi & 0,16 & & 0,11 & & 0,33 & & 0,06 & & 0,13 & & 0,15 & & 0,19 & & 0,11 & \\
\hline$\sum$ Serviços (a), (b) e (c & 0,11 & & 0,07 & & 0,26 & & 0,02 & & 0,07 & & 0,09 & & 0,13 & & 0,05 & \\
\hline
\end{tabular}

